\title{
Influences of a Quasi-stationary Front on Particulate Matter in the Low-latitude Plateau Region in China
}

\author{
Wenxuan Fan ${ }^{1}$, Jian $\mathrm{Wu}^{1^{*}}$, Xiaopeng $\mathrm{Li}^{2}$, Fangyuan $\mathrm{Yang}^{2}$, Bing Chen ${ }^{1}$, Jun Guo ${ }^{3}$ \\ ${ }^{1}$ Key Laboratory of Atmospheric Environment and Processes in the Boundary Layer over the \\ Low-Latitude Plateau Region, Department of Atmospheric Science, Yunnan University, Kunming \\ 650500, China \\ ${ }^{2}$ Meteorological Observatory of Kunming, Kunming 650118, China \\ 3 Jiangsu Climate Center, Nanjing 210008, China
}

\section{ABSTRACT}

By utilizing observation and reanalysis data and statistical methods to comprehensively assess the main characteristics of particulate matter (PM) on the low-latitude plateau (LoLaP) of southwestern China, this study analyzed the influence of the Kunming quasi-stationary front (KMQSF) on the PM concentration during winter in this region. We found that the location and intensity of the KMQSF significantly affected the distribution pattern of the PM and induced high concentrations in some areas during a typical pollution event in 2016. Furthermore, we investigated all of the KMQSF synoptic weather that occurred from 2014 till 2019 and categorized it into nine types, which produced different pollution patterns. When the KMQSF moved westward from the center of the LoLaP, the easterly wind transported PM to the western part of the region, which led to an increase in the mean daily $\mathrm{PM}_{10}$ and $\mathrm{PM}_{2.5}$ concentrations in Kunming, a capital city in that area; simultaneously, however, the $\mathrm{PM}_{10}$ and $\mathrm{PM}_{2.5}$ levels remained high in Guiyang, a capital city in the eastern part of the LoLaP. When the KMQSF gradually retreated from the western to the eastern part of the LoLaP, the PM in Kunming dropped as the westerly wind increased in strength, whereas the PM in Guiyang continued to rise as the planetary boundary layer (PBL) height (PBLH) and boundary layer dissipation (BLD) rate decreased. When the KMQSF disappeared, temperature inversion, a shallow PBL and weak BLD across the entire region caused pollutants to accumulate, resulting in the highest mean daily $\mathrm{PM}_{10}$ and $\mathrm{PM}_{2.5}$ concentrations for both cities.

Received: March 30, 2020

Revised: June 16, 2020

Accepted: August 26, 2020

Keywords: Particulate matter; Kunming quasi-stationary front, Planetary boundary layer, Atmospheric stability, Low-latitude plateau region

${ }^{*}$ Corresponding Author:

wujian@ynu.edu.cn

\section{INTRODUCTION}

Publisher:

Taiwan Association for Aerosol Research

ISSN: $1680-8584$ print

ISSN: 2071-1409 online

cc) Copyright: The Author(s).

This is an open access article distributed under the terms of the Creative Commons Attribution License (CC BY 4.0), which permits unrestricted use, distribution, and reproduction in any medium, provided the original author and source are cited.

Air pollution has been a global issue over the past several decades (Ding et al., 2013; Duncan et al., 2016; Bian et al., 2017; Davis, 2017) due to its harmful influences on human health (Lelieveld et al., 2015; Raaschou-Nielsen et al., 2017) and ecosystems as well as its severe impacts on climate (Knippertz et al., 2015; Acosta Navarro et al., 2016; Li et al., 2016; Lau et al., 2017) and synoptic systems (Gong et al., 2014; Fan et al., 2015). In addition to emissions, meteorological factors, such as wind, relative humidity $(\mathrm{RH})$, precipitation, turbulent dispersion, the planetary boundary layer (PBL), vertical temperature structure and synoptic systems, have been found to play very important roles in the day-to-day variation and the long-term trend in air quality (Ding et al., 2009; Thishan Dharshana et al., 2010; Özbay, 2012; Appelhans et al., 2013; Quan et al., 2013; Li et al., 2014; Wolf et al., 2014; Miao et al., 2015; Hou and Wu, 2016; Jiang et al., 2017; Liang et al., 2017; Tie et al., 2017). Therefore, understanding the influences of meteorological factors and atmospheric circulation on air quality is important both for improving air quality 
predictions and for formulating environmental protection strategies, especially in regions with large anthropogenic emissions.

During haze events, various meteorological factors play critical roles: moist air, a shallow PBL, temperature inversions and weak/calm wind conditions. Under weak solar radiation and stagnant, moist meteorological conditions during winter, air pollutants and water vapor accumulate in a shallow PBL (Tie et al., 2017). With an increase in aerosol pollutants, less downward direct solar radiation can reach the surface, and this reduction has a cooling effect, which in turn reduces the height of the PBL; consequently, the lower PBL altitude can further strengthen haze events that have already occurred (Li et al., 2015; Petaja et al., 2016; Yang et al., 2016; Li et al., 2017). During winter, temperature inversions can enhance the probability of severe particulate matter pollution, and many air pollution events have been found to be highly dependent on the existence of groundbased inversions in previous research (Wolf et al., 2014; Hou and Wu, 2016). In addition, the effects of wind are complex and can take many different forms. For example, weak/calm wind (i.e., stagnation) can lead to the local trapping and accumulation of pollution (Lv et al., 2017), whereas high-speed wind may favor PM resuspension and thus increase coarse PM concentrations (Zhang et al., 2018a) or quickly disperse local air pollutants (Gietl and Klemm, 2009). Furthermore, wind from different directions can introduce cleaner or more polluted air masses (Wang et al., 2017).

Except for various meteorological factors, special synoptic systems also play critical roles in PM pollution events. Jiang et al. (2017) showed that a high-pressure cell over the Tasman Sea was commonly associated with elevated pollution levels. The development of brown haze in Auckland, New Zealand, was associated with a strong northeast-southwest temperature gradient that immediately preceded the brown haze event (Salmond et al., 2016). Zhang et al. (2018b) indicated that approximately $70-74 \%$ of the "Beijing blue" came from long-term trends in favorable weather conditions, such as the North China cold vortex, which is a stable stagnant circulation system. Southwest wind or weak southerly wind dominated the warm side of the stationary front in South China in winter. Because of the weak wind, the accumulation of pollutants resulted in a wide range of haze weather in Guangxi (Liao et al., 2018a). Stationary fronts in South China, in New York City area, and in the southern Kanto Plain of Japan were revealed to be responsible for severe air pollution in these regions (Nudelman and Frizzola, 1974; Mizuno and Kondo, 1992; Lai, 2015; Liao et al., 2018a).

The Kunming quasi-stationary front (KMQSF) is a famous synoptic system in China and often appears in the eastern part of the low-latitude plateau (LoLaP) in southwestern China during winter and spring, whose monthly average frequency is 11.8 days month ${ }^{-1}$ from November to April for the period of $1961-2010$. Additionally, $61.5 \%$ of the KMQSF was located east of $103^{\circ} \mathrm{E}$ during 1961-2010. This synoptic system is usually caused by the confrontation between the southwestern warm air and the cold air from the polar region that is stopped by the Tibetan Plateau and the LoLaP (Duan et al., 2017), and there are significant differences in the weather and climatic characteristics of the pre-frontal and post-frontal sectors (Fig. 1(a)) (Sheng et al., 2015). Therefore, the influences of the KMQSF on air pollution in LoLaP region should be clearly investigated.

The air quality in LoLaP is usually good, and observations have revealed that the aerosol optical depth (AOD) was between 0.1 and 0.2 for the period from March 2000 to February 2010 in southwestern China (Luo et al., 2014). In addition, the hourly average concentrations of $\mathrm{PM}_{2.5}$, $\mathrm{PM}_{10}$ and black carbon (BC) in the city of Tengchong, a county in LoLaP and $750 \mathrm{~km}$ to the west of Kunming, were $30 \mu \mathrm{g} \mathrm{m}^{-3}, 32 \mu \mathrm{g} \mathrm{m}^{-3}$, and $420 \mathrm{ng} \mathrm{m}^{-3}$, respectively (Engling et al., 2011). These measurements of the particulate mass concentrations were conducted from April 7 to May 24, 2004, and coincided with the annual intensive biomass burning season in South and Southeast Asia, which can be regarded as the severest air pollution in this area (Engling et al., 2011). According to the daily air pollution measure in all cities in China between 1980 and 2005, a significant increasing trend in haziness has been revealed in LoLaP in recent years (Che et al., 2009). The observed increase in pollution should be investigated from the perspective of the geographic position and weather events, especially the influence of the KMQSF. This work analyzes the relationship between PM pollution and KMQSF. The stationary fronts frequently occur in the world, so this work is expected to be of some reference value to the study of air pollution in stationary front regions. The data and methods used in this research are presented in Section 2, and analysis of a typical pollution event is presented in Section 3, the relationship between fine particles and KMQSF in Section 4, and the conclusions are summarized in Section 5. 


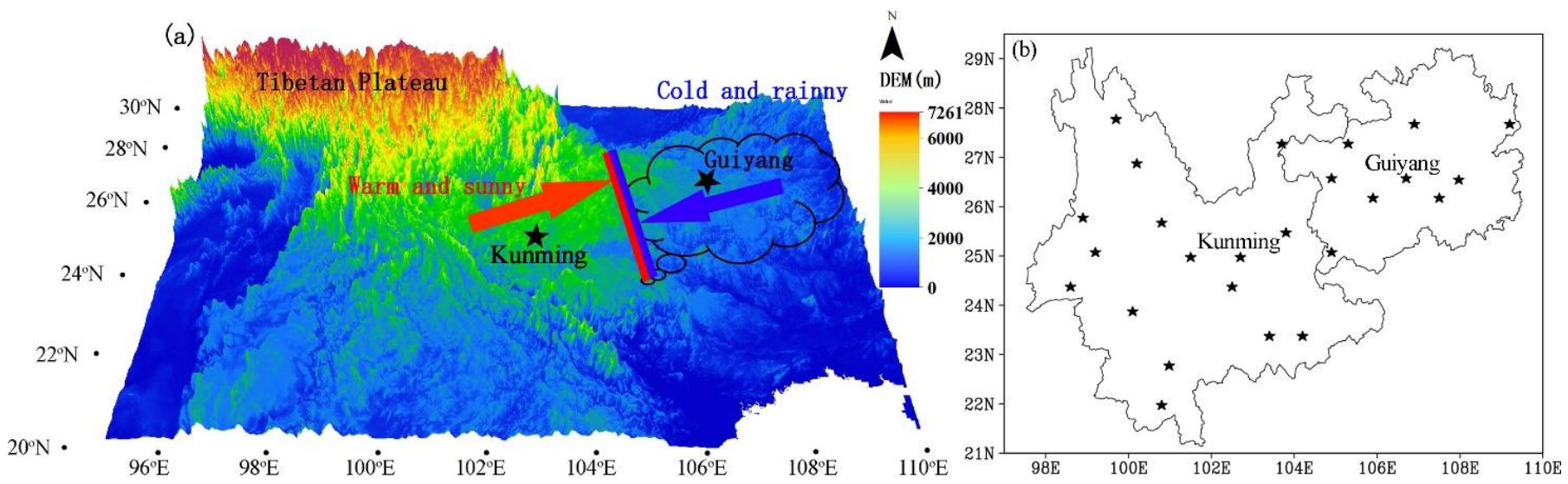

Fig. 1. Topographic maps of LoLaP with (a) the KMQSF and (b) 25 cities. The KMQSF appeared in the eastern region of LoLaP is usually caused by the confrontation between the southwestern warm air and the cold air from the polar region that is stopped by the Tibetan Plateau.

\section{DATA AND METHODS}

\subsection{PM Concentration Data}

Observation was conducted at two stations of the Key Laboratory of Atmospheric Environment and Processes in the Boundary Layer (AEPBL) in LoLaP region from November 2016 to May 2017. The two stations were established on two campuses, Donglu $\left(102.70^{\circ} \mathrm{E}\right.$ and $25.06^{\circ} \mathrm{N}$ at $1914 \mathrm{~m}$ above sea level) and Chenggong $\left(102.85^{\circ} \mathrm{E}\right.$ and $24.83^{\circ} \mathrm{N}$ at $1920 \mathrm{~m}$ above sea level) of Yunnan University, which represent typical characteristics of downtown and suburban regions, respectively. The downtown observation at the Donglu station was used in this study.

The $\mathrm{PM}_{10}, \mathrm{PM}_{2.5}$ and $\mathrm{PM}_{1}$ mass and number concentrations were measured at the Donglu and Chenggong stations using an environmental dust monitor (EDM 180-MC; GRIMM Aerosol Technik GmbH \& Co. KG) (Jung et al., 2015; Khan et al., 2016) at an interval of $5 \mathrm{~min}$. The precision of the Grimm 180 instrument is $\pm 2 \%$ for $\mathrm{PM}_{10}, \mathrm{PM}_{2.5}$ and $\mathrm{PM}_{1}$, and the environmental dust monitor was annually calibrated.

Hourly observations of surface $\mathrm{PM}_{10}$ and $\mathrm{PM}_{2.5}$ concentrations on December 1-14, 2016, in Guiyang $\left(106.69^{\circ} \mathrm{E}, 26.57^{\circ} \mathrm{E}\right)$ in LoLaP region (Fig. $\left.1(\mathrm{~b})\right)$ are derived from the real-time platform of urban air quality of China's National Environmental Monitoring Centre (http://106.37.208.233:20035/), which represents an average of all sites in the city. And hourly observations of surface $\mathrm{PM}_{10}$ and $\mathrm{PM}_{2.5}$ concentrations on November-next February from 2014 to 2019 at 25 cities in LoLaP region were also used (Fig. 1(b)), which was interpolated into grid data between $97-110^{\circ} \mathrm{E}, 21-30^{\circ} \mathrm{N}$ at a resolution of $0.5^{\circ} \times 0.5^{\circ}$.

\subsection{Meteorological Data}

The hourly air temperature, $\mathrm{RH}$, wind speed, wind direction and precipitation data that were observed in Kunming and Guiyang were used in this study. The two additional stations are managed by the Kunming Meteorological Bureau; the first site is approximately $1 \mathrm{~km}$ southeast of the YNU Donglu station $\left(102.71^{\circ} \mathrm{E}, 25.06^{\circ} \mathrm{N}\right)$, and the second site is the standard meteorological station $\left(102.65^{\circ} \mathrm{E}, 25^{\circ} \mathrm{N}\right)$, which is located approximately $6 \mathrm{~km}$ southwest of the YNU Donglu station.

In addition, ERA-Interim reanalysis data four times day by day on November-next February from 2014 to 2019 between $97-110^{\circ} \mathrm{E}, 21-30^{\circ} \mathrm{N}$ at a resolution of $0.125^{\circ} \times 0.125^{\circ}$ were used in this research and included the wind speed at a height of $10 \mathrm{~m}$ above the surface, temperature at a height of $2 \mathrm{~m}$, low cloud cover, PBL height (PBLH) and boundary layer dissipation (BLD), wind speed, temperature and RH in the upper 37 levels above $1000 \mathrm{hPa}$ (Dee et al., 2011; Tavolato and Isaksen, 2011).

\subsection{Meteorological Diagnostic Method}

The scalar frontogenesis function was introduced to display the development and change in 
the KMQSF (Zhu et al., 2000), and this function is presented in Eq. (1):

$$
\begin{aligned}
F & =-\frac{1}{|\nabla \theta|}\left[\left(\frac{\partial \theta}{\partial x}\right)^{2} \frac{\partial u}{\partial x}+\left(\frac{\partial \theta}{\partial y}\right)^{2} \frac{\partial v}{\partial y}+\frac{\partial \theta}{\partial x} \frac{\partial \theta}{\partial y}\left(\frac{\partial u}{\partial x}+\frac{\partial v}{\partial y}\right)\right]-\frac{1}{|\nabla \theta|}\left(\frac{\partial \theta}{\partial x} \frac{\partial \omega}{\partial x}+\frac{\partial \theta}{\partial y} \frac{\partial \omega}{\partial y}\right) \frac{\partial \theta}{\partial p} \\
& +\frac{1}{|\nabla \theta|}\left[\frac{\partial \theta}{\partial x} \frac{\partial}{\partial x}\left(\frac{\partial \theta}{d t}\right)+\frac{\partial \theta}{\partial y} \frac{\partial}{\partial y}\left(\frac{d \theta}{d t}\right)\right]
\end{aligned}
$$

where $|\nabla \theta|$ can be expanded using Eq. (2):

$$
|\nabla \theta|=\sqrt{\left(\frac{\partial \theta}{\partial x}\right)^{2}+\left(\frac{\partial \theta}{\partial y}\right)^{2}}
$$

Eq. (1) includes the individual effects on the scalar frontogenesis function from the adiabatic heating term, vertical motion tilt term, horizontal divergence term and horizontal deformation term. In addition, $F>0$ indicates frontogenesis, and $F<0$ indicates frontolysis. The scalar frontogenesis function is used to confirm the location of the KMQSF. The usual criterion of the KMQSF can be represented by the isotherm intensive area and the west-east wind transition zone, which is associated with the ground region $|\nabla \theta|>5 \mathrm{~K} 100-\mathrm{km}^{-1}$, the scalar frontogenesis function $\mathrm{F}>0$ (Duan et al., 2017).

The bulk Richardson number, $\mathrm{Rb}$, is defined as the ratio of turbulence associated with buoyancy to that induced by mechanical shear (Stull, 1988), which is expressed as:

$$
R b=\frac{g}{\theta} \frac{\frac{\Delta \theta}{\Delta z}}{\left(\frac{\Delta u}{\Delta z}\right)^{2}+\left(\frac{\Delta v}{\Delta z}\right)^{2}}=\frac{g}{\theta} \frac{\Delta \theta}{u^{2}+v^{2}} z
$$

where $z$ denotes height above ground, $g$ is the acceleration of gravity, $\theta$ is the potential temperature, $u$ and $v$ are the component of wind speed. In the limit of layer thickness becoming small, the bulk Richardson number approaches the gradient Richardson number, for which a critical Richardson number, $\mathrm{Ri}_{\mathrm{c}}$, is roughly 0.25 . Gradient Richardson numbers less than this critical value are dynamically unstable and likely to become or remain turbulent.

\section{INFLUENCES OF KMQSF ON A TYPICAL AIR POLLUTION EVENT}

\subsection{General State of this Event}

The observed average $\mathrm{PM}_{10}, \mathrm{PM}_{2.5}$ and $\mathrm{PM}_{1}$ mass concentration at the Donglu station located in southeast Kunming were 62.3, 34.4 and $28.0 \mu \mathrm{g} \mathrm{m}^{-3}$, respectively, from November 2016 to May 2017. However, the daily mean concentration of $\mathrm{PM}_{2.5}$ at Donglu on December 9, 2016, was $89.6 \mu \mathrm{g} \mathrm{m}^{-3}$, which was higher than $75 \mu \mathrm{g} \mathrm{m}^{-3}$ exceeding the Grade II standard in China and was the only pollution event in the research period. In addition, $\mathrm{PM}_{10}$ and $\mathrm{PM}_{2.5}$ concentrations synchronously increased during December 4-9, 2016, in the whole LoLaP (Fig. 2), while the highpollution event usually appeared in eastern LoLaP. A typical pollution event was selected for deeper analysis to reveal its characteristics and causes.

The continuously accumulated of PM in the typical pollution event was between two KMQSF processes on December 2-3 and after December 11, respectively (Fig. 3). The distribution of PM concentrations showed the similar structure to the KMQSF, and the isolines of PM concentrations was northwest-southeast. A discontinuity in wind direction and a significant horizontal potential temperature gradient could be used to diagnose KMQSF, and the pre-frontal and post-frontal wind speed decided the location of KMQSF, which usually caused the different weather in west and east parts of LoLaP. The KMQSF marked by a significant horizontal potential temperature gradient $\left(|\nabla \theta|>5 \mathrm{~K} 100-\mathrm{km}^{-1}\right)$ and wind shear. When the KMQSF appeared and the westerly was 

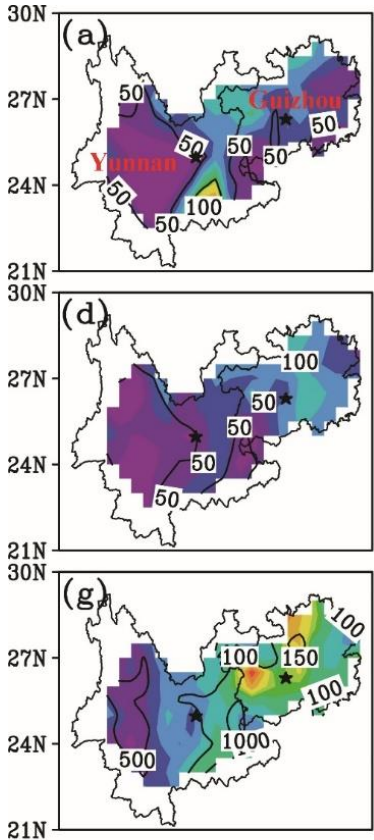

$30 \mathrm{~N}$

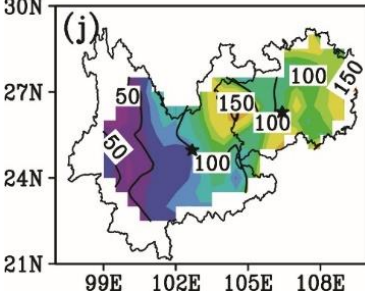

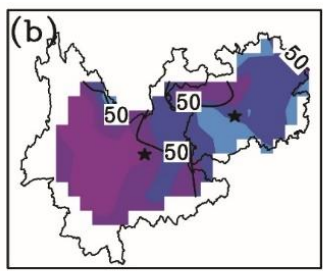
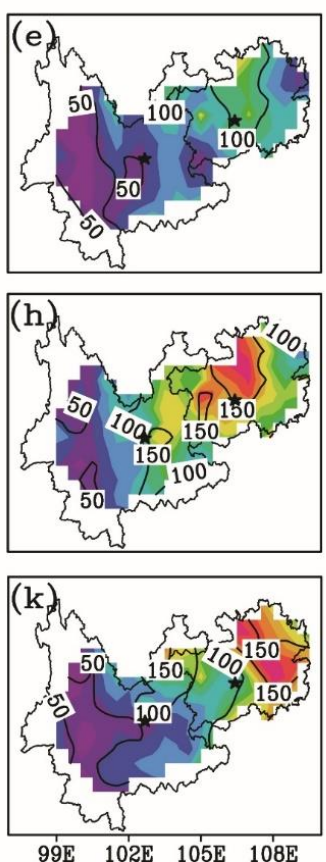

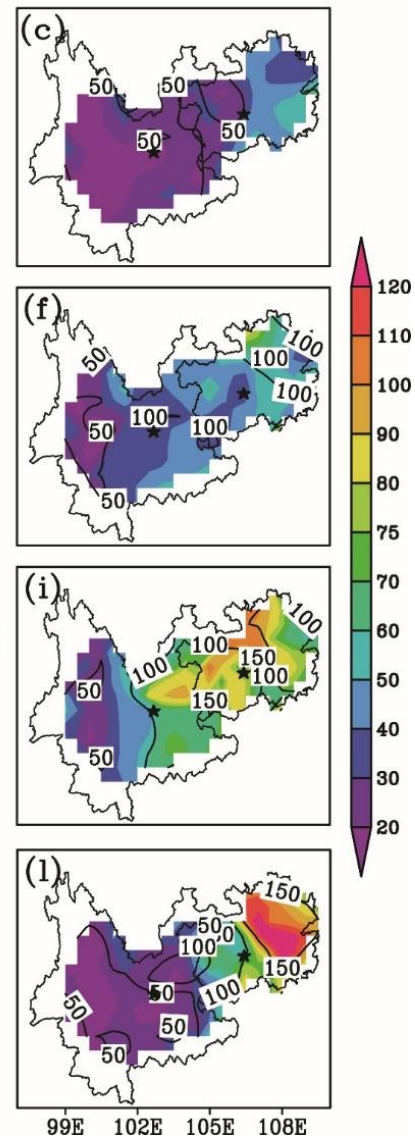

Fig. 2. The distribution of daily average $\mathrm{PM}_{10}\left(\mu \mathrm{g} \mathrm{m}^{-3}\right.$; contour) and $\mathrm{PM}_{2.5}\left(\mu \mathrm{g} \mathrm{m}^{-3}\right.$; shaded) in LoLaP during the period of (a-I) December 1-12, 2016.

stronger, the low values of PM in western LoLaP will be push to eastern LoLaP by high wind speed. When the KMQSF disappeared and this condition maintained several days, the westerly and the easterly weakened (Fig. 3), the PM accumulated.

In general, the PM concentrations were higher in eastern LoLaP and lower in western LoLaP (Fig. 2). On December 1-3, the low-values area of PM in western LoLaP gradually expanded eastward (Figs. 2(a)-2(c)), when the westerly gradually strengthened in western LoLaP and the KMQSF appeared in the middle of LoLaP (Figs. 3(a)-3(c)). From December 4-9, the PM in the whole LoLaP increased (Figs. 2(d)-2(j)), and the daily mean concentration of $\mathrm{PM}_{2.5}$ reached $80 \mu \mathrm{g}$ $\mathrm{m}^{-3}$ near Kunming and $120 \mu \mathrm{g} \mathrm{m}^{-3}$ to the northeastern LoLaP on December 8. The wind speed was always lower in whole LoLaP in this period and the KMQSF disappeared in the middle of LoLaP (Figs. 3(d)-3(j)). After December 10, the low-values area of PM in western LoLaP expanded eastward again, when the westerly strengthened. A PM area with $\mathrm{PM}_{2.5}$ of $120 \mu \mathrm{g} \mathrm{m}^{-3}$ appeared on December 11 and 12, which was trapped in eastern LoLaP (Figs. 3(k)-3(I)).

In general, the highest PM concentration mainly occurred at night, associating with a stable nocturnal boundary layer. The lower PBLH, smaller BLD and $\mathrm{Rb}>0.25$ could represent a stable boundary layer. Fig. 4 shows distribution of PBLH, BLD and Rb at 18:00 UTC (02:00 BJT) from December 1 to 12, 2016. When the KMQSF appeared in the middle of LoLaP before December 3, the PBLH was higher, the BLD was stronger, dynamically unstable area was larger (Figs. 4(a)-4(c)), and the PM concentration was lower. During night from December 4 to 9, except for December 5 , the stable PBLH were lower than $50 \mathrm{~m}$ and the BLD were lower (Figs. 4(d)-4(i)); when the PM reached the highest concentrations both in Kunming and Guiyang on December 8 , the BLD were lower than $3 \times 10^{4} \mathrm{~J} \mathrm{~m}^{-2}$ (Fig. 4(h)). Obviously, local pollution accumulation under the stable PBL and weak dissipation was the main reason inducing this pollution episode. When the KMQSF reappeared in the middle of LoLaP after December 11, the PBLH and the BLD increased both (Figs. $4(\mathrm{k})-4(\mathrm{I}))$, the low PM area in western LoLaP was pushed to eastern LoLaP. The high-PM 

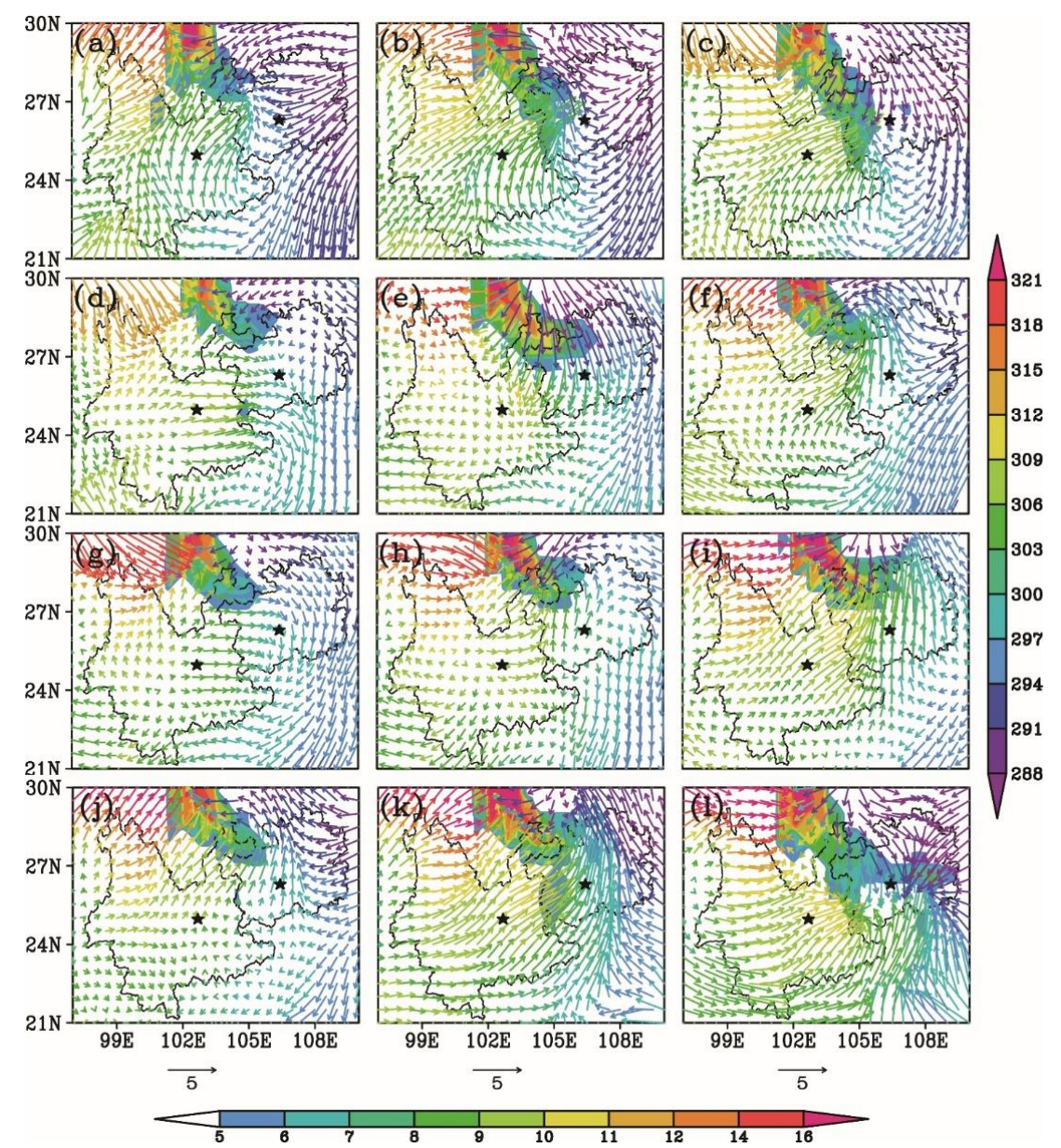

Fig. 3. The distribution of horizontal potential temperature gradient $\left(\mathrm{K} 100-\mathrm{km}^{-1}\right.$; shaded, horizontal bar), wind $\left(\mathrm{m} \mathrm{s}^{-1}\right)$ and potential temperature ( $\mathrm{K}$; vertical bar) at the surface in LoLaP during the period of (a-l) December 1-12, 2016.

pollution was obviously blocked to the east of the frontal line of the KMQSF. The change of KMQSF was well matched with the change of PM concentrations, and the KMQSF played an important role in this pollution episode.

\subsection{Temporal Evolution of PM Concentration in Western and Eastern LoLaP}

In order to analyze the causes of this pollution event in detail, the temporal changes in $\mathrm{PM}_{10}$, $\mathrm{PM}_{2.5}$ and $\mathrm{PM}_{1}$ at Donglu in Kunming and the temporal changes in $\mathrm{PM}_{10}$ and $\mathrm{PM}_{2.5}$ in Guiyang, as well as the meteorological parameters (Fig. 5), are selected for further analysis, and a comparison between the western LoLaP site and the eastern LoLaP site can be made. The concentrations of $\mathrm{PM}_{10}, \mathrm{PM}_{2.5}$ and $\mathrm{PM}_{1}$ at Donglu and Guiyang during December 1-3 were lower (Figs. 5(d) and $5(\mathrm{~h})$ ). Under the control of the KMQSF, the water vapor in the west side of the stationary front is sufficient, which caused the low cloud (Fig. 6). The atmosphere was cleaner after the frontal precipitation process during December 1-2 at Donglu and during December 2-3 in Guiyang, and this state was the pre-pollution period of this episode.

The period of December 4-9 was the pollution accumulation phase of the pollution episode. The hourly maximum concentrations of $\mathrm{PM}_{10}, \mathrm{PM}_{2.5}$ and $\mathrm{PM}_{1}$ on December 4 were 148.7, 86.8 and $69.5 \mu \mathrm{g} \mathrm{m}^{-3}$, respectively, and they increased to $228.0,133.1$ and $110.2 \mu \mathrm{g} \mathrm{m}^{-3}$ on December 9 at Donglu (Fig. 5(d)). The hourly maximum concentrations of $\mathrm{PM}_{10}$ and $\mathrm{PM}_{2.5}$ reached 273.9 and $188.9 \mu \mathrm{g} \mathrm{m}^{-3}$ on December 8 in Guiyang (Fig. $5(\mathrm{~h})$ ). The growth rates of hourly minimum PM10, $\mathrm{PM}_{2.5}$ and $\mathrm{PM}_{1}$ at Donglu changed from $7.9 \mu \mathrm{g} \mathrm{m}^{-3} 24 \mathrm{~h}^{-1}$ on December 4 to $25.8 \mu \mathrm{g} \mathrm{m}^{-3} 24-\mathrm{h}^{-1}$ on December 7, from $4.0 \mu \mathrm{g} \mathrm{m}{ }^{-3} 24-\mathrm{h}^{-1}$ to $19.0 \mu \mathrm{g} \mathrm{m}^{-3} 24-\mathrm{h}^{-1}$, and from $3.2 \mu \mathrm{g} \mathrm{m}^{-3} 24-\mathrm{h}^{-1}$ to $15.6 \mu \mathrm{g} \mathrm{m}^{-3} 24-\mathrm{h}^{-1}$, respectively. The growth rates of hourly minimum $\mathrm{PM}_{10}$ and $\mathrm{PM}_{2.5}$ in Guiyang 

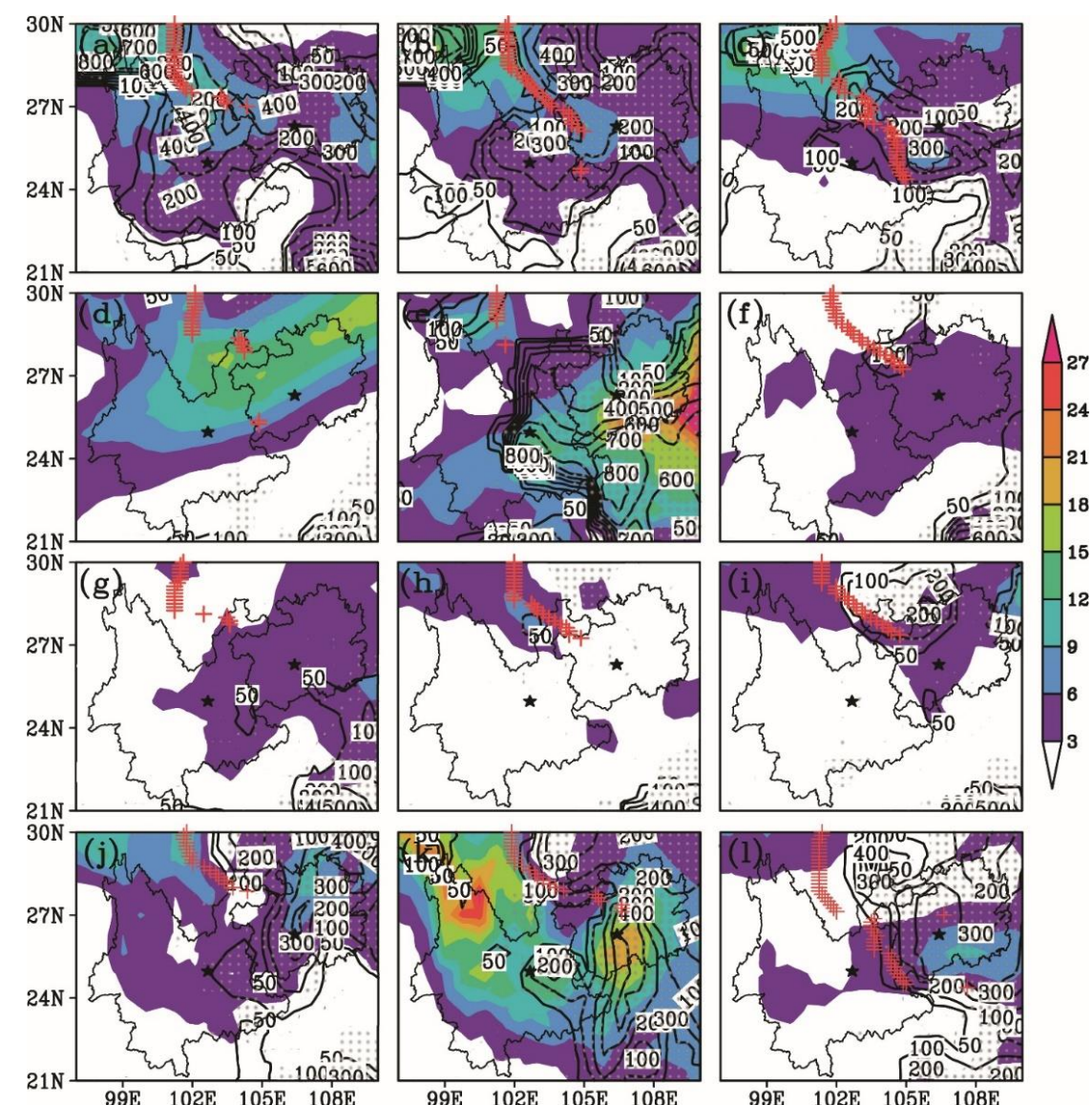

Fig. 4. The distribution of boundary layer height ( $\mathrm{m}$; contour), boundary layer dissipation $\left(10^{4} \mathrm{~J} \mathrm{~m}^{-2}\right.$; shaded) and $\mathrm{Rb}(<0.25$; dots) in LoLaP during the period of (a-l) December 1-12, 2016. The red + represents the location of the KMQSF.

changed from $22.3 \mu \mathrm{g} \mathrm{m}^{-3} 24-\mathrm{h}^{-1}$ on December 4 to $57.1 \mu \mathrm{g} \mathrm{m}^{-3} 24-\mathrm{h}^{-1}$ on December 7 , and from $16.3 \mu \mathrm{g} \mathrm{m}^{-3} 24-\mathrm{h}^{-1}$ to $35.2 \mu \mathrm{g} \mathrm{m}^{-3} 24-\mathrm{h}^{-1}$, respectively. The positive growth rates of hourly minimum PM meant that the background values of the PM were increasing and there was distinct accumulation of the PM, and the accumulation occurred at Donglu and in Guiyang both.

During the pollution accumulation phase, wind speed remained at lower levels at Donglu, with an hourly maximum speed of $1.3 \mathrm{~m} \mathrm{~s}^{-1}$ before December 8 , and it is southerly in daytime and northerly at night (Fig. 5(a)). The nocturnal wind from the north of the Donglu station might contain a lot of pollution gas from the Jindinshan industrial area (Shi et al., 2016), which caused the hourly PM maximum at night at Donglu. The mean wind speed in Guiyang was larger than that at Donglu, several changes of wind direction happened from December 4 to 10 with relative lower wind speed (Fig. 6(e)), the air from surrounding region could be transported to Guiyang. $\mathrm{RH}$ was $81.3 \%$ at night on December 6 at Donglu, and then $\mathrm{RH}$ continually increased during both day and night until reaching $96.0 \%$ at night on December 9 (Fig. 5(b)). The maximum RH at night on December 8 and 9 also reached $98 \%$ and $97 \%$ without rain in Guiyang (Fig. 5(f)). Under high $\mathrm{RH}$ (i.e., $>60-80 \%$ ), the volume of aerosol particles can significantly increase when water vapor is absorbed onto the surface of these particles, and the enlarged aerosol surfaces/volumes lead to more rapid multiphase reactions and secondary aerosol formation, which results in elevated aerosol concentrations (Tie et al., 2017). In addition, the ground inversion layer (TIL) always existed (Figs. 5(c) and 5(h)). The low wind speed, high $\mathrm{RH}$, and TIL induced stagnant conditions, which corresponded to the disappearance of the KMQSF and favored the accumulation of aerosol particles and secondary aerosol formation.

The RH was still high on December 10 at Donglu (Fig. 5(b)), and a stable TIL maintained (Fig. 5(c)). These conditions caused high concentrations of fine particles until midnight, and then the particle mass pollutant was dispersed by higher wind speeds and stronger turbulence on 


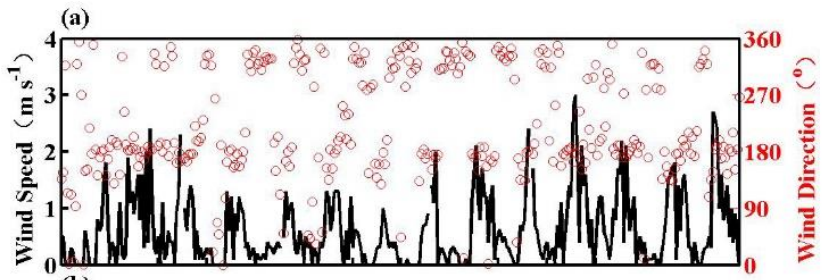

(e)
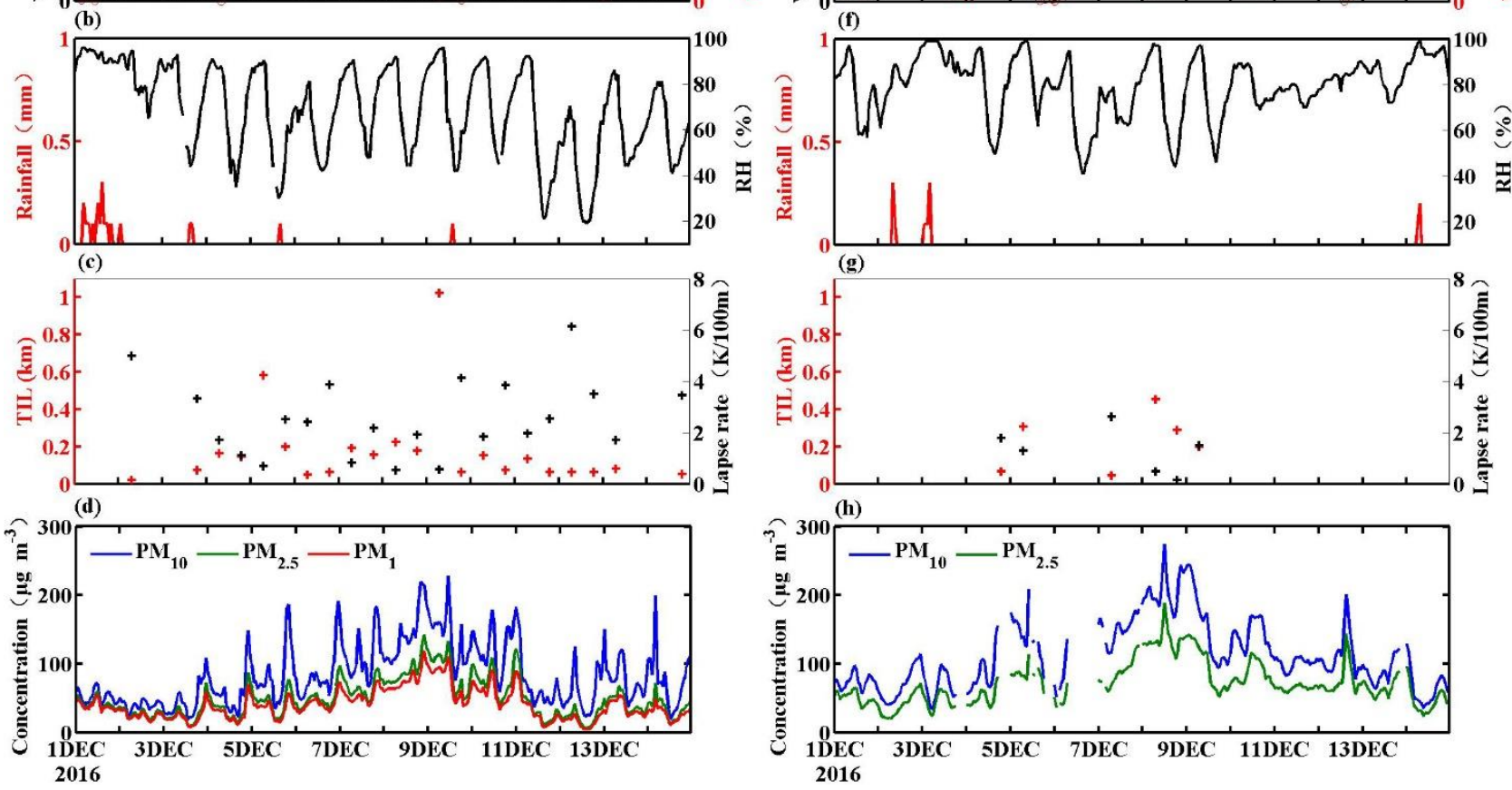

Fig. 5. Hourly variations in (a) wind speed and wind direction, (b) precipitation and $\mathrm{RH}$, (c) thickness and lapse rate of the ground inversion layer, and (d) $\mathrm{PM}_{10}, \mathrm{PM}_{2.5}$ and $\mathrm{PM}_{1}$ at Donglu in Kunming. (e), (f), (g) and (h) are the same as (a), (b), (c) and (d), respectively, but for Guiyang.

December 11 and 12 (Figs. 5(a) and 5(d)). The RH abruptly decreased, which meant a weather change and a warm and dry airflow immigration in western LoLaP. The TIL disappeared in Guiyang on December 10 (Fig. 5(g)), wind speed and RH gradually increased on December 11 and 12 (Figs. 5(e) and 5(f)), the southerly changed into easterly and wind speed increased on December 12 (Fig. 5(e)), and the low cloud moved westward from eastern LoLaP (Fig. 6(c)), which meant a cold and moist airflow appeared in eastern LoLaP. The PM in Guiyang also decreased in higher wind speeds but was still higher than that at Donglu in influence of pollution transport from surrounding region. This final period of the pollution episode was called the collapsing period, which corresponded to the appearance of the KMQSF (Fig. 6).

The wind speed remained at a relatively high level during December 13-14, with hourly maximum speeds of 1.8 and $2.7 \mathrm{~m} \mathrm{~s}^{-1}$ at Donglu and hourly maximum speeds of 3.9 and $5.5 \mathrm{~m} \mathrm{~s}^{-1}$ in Guiyang (Figs. 5(a) and 5(e)). This change was associated with a decrease in the maximum of nocturnal RH from $85.9 \%$ to $81.1 \%$ at Donglu (Fig. 5(b)), and with an increase in the maximum of nocturnal RH from $91 \%$ to $99 \%$ in Guiyang (Fig. 5(f)). These facts indicate that warm and dry westerly winds in western LoLaP and cold and moist easterly winds in eastern LoLaP had strengthened. The KMQSF moved westward with low clouds (Fig. 6), and rainfall occurred in Guiyang and removed PM (Figs. 5(f) and 5(h)).

Temperature inversion can restrain the convection and dispersion of air pollutants due to weaker turbulence, and temperature inversion can also lead to a weaker surface wind speed relative to neutral and unstable stratification according to the logarithmic velocity profile. These conditions can also further decrease the transport of air pollutants. Therefore, temperature inversion favors the accumulation of air pollutants. From December 4-12, there was a ground inversion layer in Kunming at 08:00 and 20:00, and this inversion layer was usually thinner and stronger at 20:00 than at 08:00 (Fig. 5(c)), which was produced at night and disappeared in 


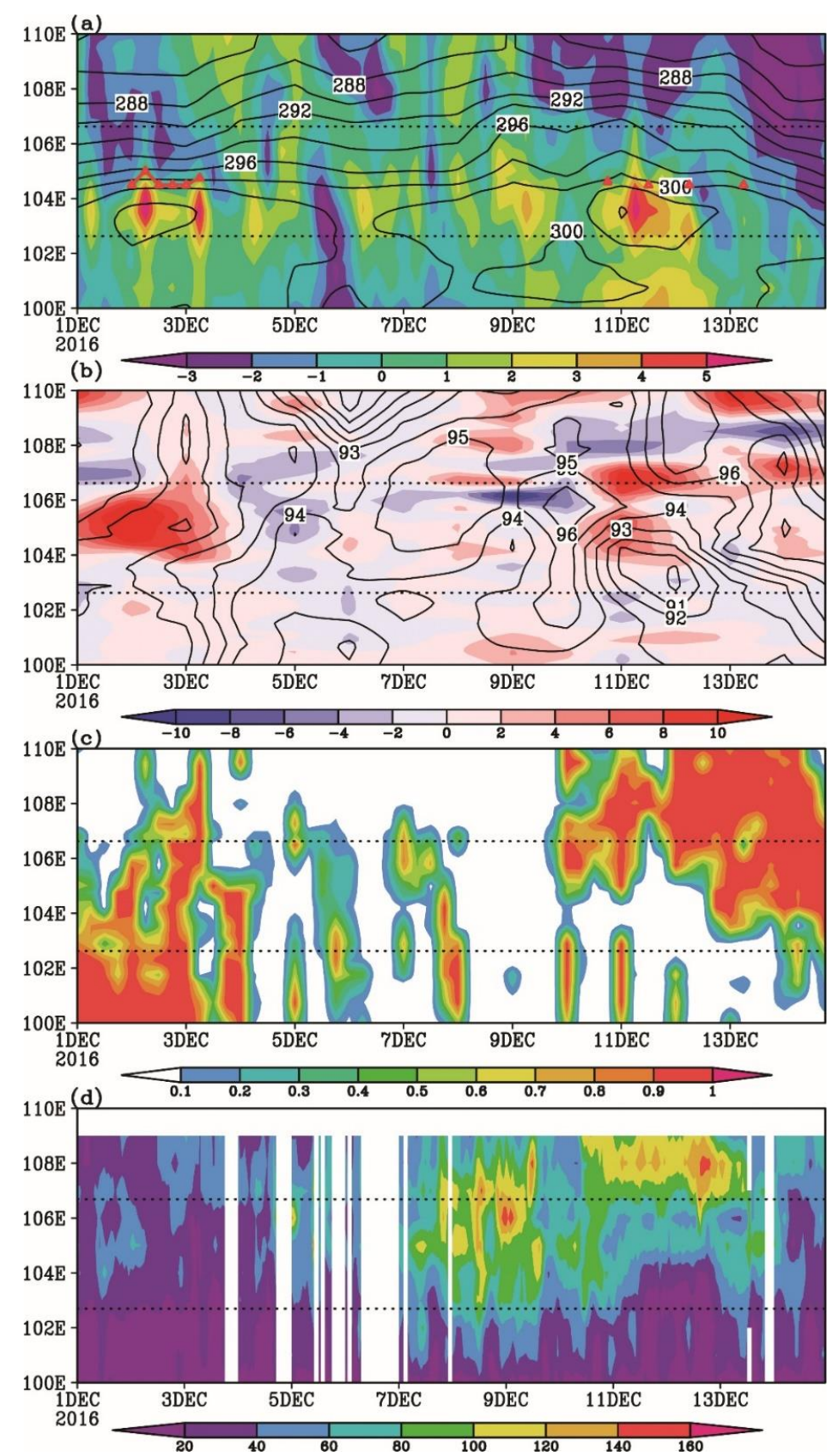

Fig. 6. Spatiotemporal distributions of (a) the potential temperature ( $\mathrm{K}$; contour) and zonal wind $\left(\mathrm{m} \mathrm{s}^{-1}\right.$; shaded) at the surface (the red line represents the location of the front line), (b) the RH (\%) at the surface and the scalar frontogenesis function at $850 \mathrm{hPa}\left(10^{-10} \mathrm{~K} \mathrm{~m}^{-1} \mathrm{~s}^{-1}\right.$; shaded), (c) low cloud cover and (d) $\mathrm{PM}_{2.5}$ in the vertical cross section across Kunming $\left(25^{\circ} \mathrm{N}, 102.625^{\circ} \mathrm{E}\right)$ and Guiyang $\left(26.625^{\circ} \mathrm{N}, 106.625^{\circ} \mathrm{E}\right)\left(\mu \mathrm{g} \mathrm{m}^{-3}\right)$ during the period of December $1-14,2016$, and the situations of two cities are indicated by two dotted lines respectively.

daytime. The surface cooling process at night might be caused by the strong upward infrared radiation and the cold air sliding down the hillside during nocturnal hours. These results support the formation of a ground temperature inversion (Duan et al., 2014; Wolf et al., 2014). The rate of the TIL appearing in Kunming is obviously higher than that in Guiyang, because Kunming is located in a small basin surrounded by mountains and along the northwestern edge of a lake with the valley wind, warm advection, and infrared radiation emission of the surface (Duan et al., 2014). The temporal characteristics of TIL indicated that there was absolute stability near the ground during this pollution episode, in particular from December 5 to 10, which supplied enough 
time for the accumulation of air pollutants, production of chemical reactions among pollutant species, and formation of secondary aerosols. The thickness of the inversion layer reached 1024 $\mathrm{m}$ at 08:00 on December 9, which matched the timing of the subsequent peak value of aerosols. The thicker inversion layer was not easy to disappear immediately, so the hourly maximum concentrations of PM appeared at 11:00 before it started to rain. The TIL appeared on December 4-9 and there was a ground inversion layer at 08:00 and 20:00 on December 8 in Guiyang (Fig. 5(g)), when clear sky also appeared in Guiyang (Fig. 6(c)). The similar calm weather supported the pollution event appeared in Kunming and Guiyang both. Otherwise, there were some different between western and eastern LoLaP, the stability in western LoLaP was obviously higher than that in eastern LoLaP, which shown lower wind speed and long-term maintain of TIL.

Fig. 7 shows a backward trajectory analysis. Using the Hybrid Single-Particle Lagrangian Integrated Trajectory (HYSPLIT) model driven with the Global Data Assimilation System (GDAS) output, the 48-h backward trajectories of Kunming and Guiyang from December 4-10, 2016, were analyzed. The air over Kunming was mainly sourced from cleaner southwest direction during the study period, except for December 6 and 7. During the pollution accumulation period from December 4-9, the wind speed decreased gradually and slowly changed to ground-toground airflow, and the wind nearly stopped on December 9. Although the wind speed increased on December 10, it remained a ground-to-ground airflow. There were more complicated air sources in Guiyang. Except for December 6 and 7, the air over Guiyang in $48 \mathrm{~h}$ was mainly from the north and south direction, and the wind also nearly stopped on December 8 and 9. On December 6, the air over Guiyang in $48 \mathrm{~h}$ was from Inner Mongolia and turned to northeast wind near $30^{\circ} \mathrm{N}$, and it was easterly in east of Guiyang (Fig. 3(f)). The path on December 7 was similar to that on December 6 , but the wind speed decreased and it turned to southerly before reaching Guiyang. Thus, it is reasonable to assume that the source of this pollution event in Kunming was local, and there were pollution sources from surrounding areas in Guiyang, except for local source.

This typical pollution episode was triggered by the combined effects of synoptic conditions, decreasing wind speed, increasing $\mathrm{RH}$, and ground temperature inversion. During the sustained synoptic process, fine particles could continuously accumulate, and secondary aerosols could continuously form and wet-grow into larger aerosols; therefore, a light haze episode formed. When the synoptic conditions changed again, e.g., when the KMQSF migrated, wind disrupted the static and stable weather, and the haze dissipated.
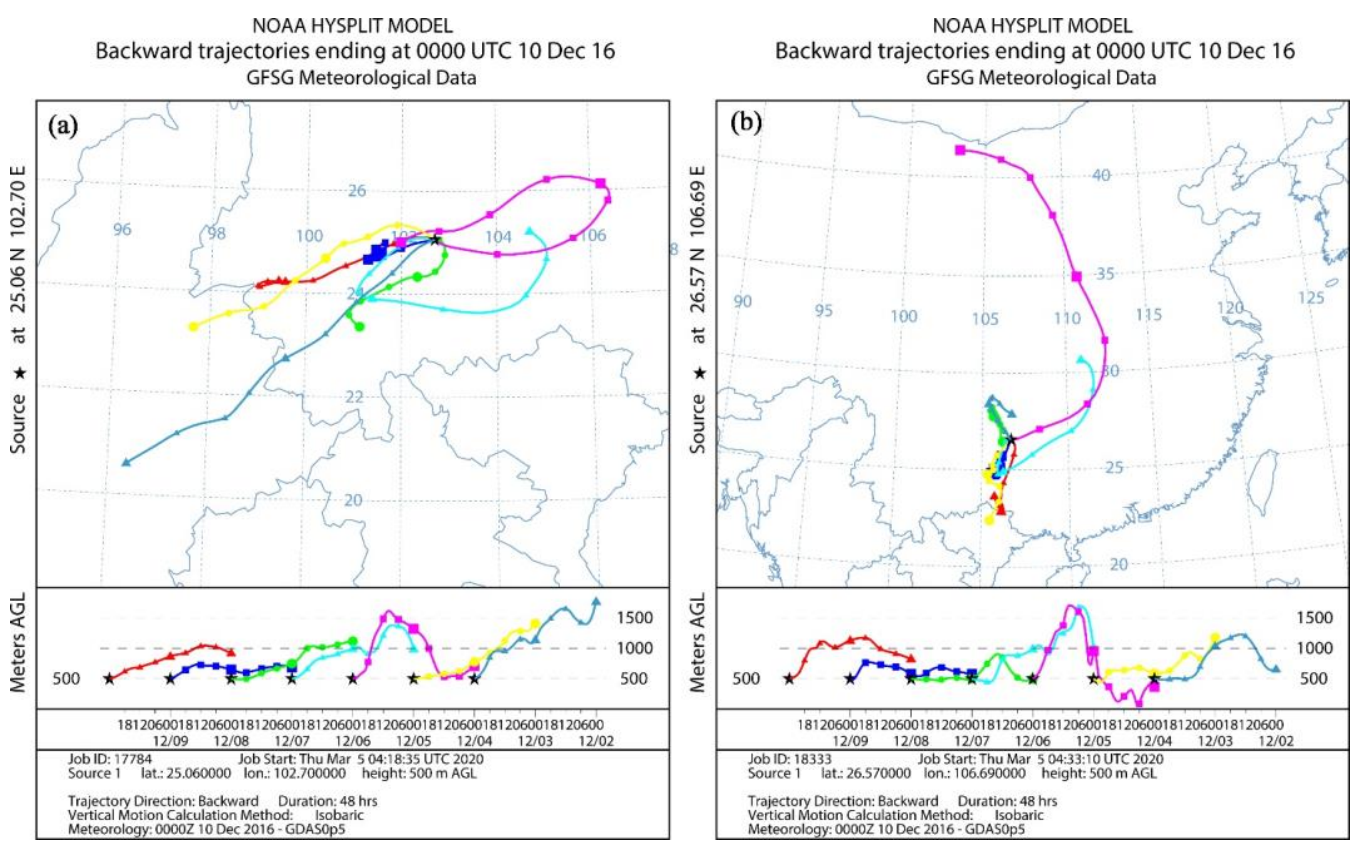

Fig. 7. The 48-h backward trajectories of air parcels ending at 500-m altitude over (a) Kunming and (b) Guiyang on December 4-10. Note that trajectories were colored with ending date. 


\section{KMQSF PATTERNS AND INFLUENCES ON AIR POLLUTION IN RECENT FIVE YEARS}

The KMQSF often appears in the eastern region of LoLaP during winter and spring, and it seems that the location and intensity of KMQSF influenced the concentrations and distribution of PM from Section 3. The meteorological factors and PM data on November-next February 2014-2019 were used to analyze the relationship between them; there are 601 days in total. The selforganizing maps (SOMs) were used to distinguish the patterns of KMQSF (Mattingly et al., 2016; Gibson et al., 2017; Francis et al., 2018), and the horizontal potential temperature gradient and zonal wind were used as input data of SOM. Three different SOM configurations were tested: a 6 -node SOM ( 3 columns $\times 2$ rows), a 9-node SOM ( 3 columns $\times 3$ rows) and a 12-node SOM ( 3 columns $\times 4$ rows), applied to standardized horizontal potential temperature gradient data and zonal wind speed data. From these options, the output from the 9-node SOM is easier to interpret than the 6-node and 12-node SOM, and it also includes a sufficient number of nodes to represent the KMQSF; therefore, the 9-node SOM was chosen as the best classification for further analysis (Table 1).

The horizontal potential temperature gradient was matched with the transformation zone of westerly and easterly. When the easterly was strong, the KMQSF would be pushed to west, and when the westerly was strong, the KMQSF would be pushed back to east. The whole eastern LoLaP and middle LoLaP were controlled by the strong and cold northeast wind under Pattern 1 (Fig. 8(a)). There were 246 days in Pattern 2-5, in which the KMQSF located between western and eastern LoLaP, and eastern LoLaP prevailed cold northeasterly and western LoLaP was covered by warm southwest wind (Figs. 8(b)-8(e)). The southwesterly was very strong under Pattern 6 and 7, southerly occupied the whole eastern LoLaP and the KMQSF was pushed to the northern LoLaP (Figs. 8(f) and 5(g)). Pattern 8 includes 82 days, the KMQSF located middle LoLaP, but the KMQSF was weaker, associating with southerly in eastern LoLaP (Fig. 8(h)).

Fig. 9 shows distribution of PBLH, BLD and Rb at 18:00 UTC (02:00 BJT) and Fig. 10 shows distribution of daily mean $\mathrm{PM}_{10}$ and $\mathrm{PM}_{2.5}$. In general, the PBLH was higher and BLD was stronger near the KMQSF, and the high-values areas of the PBLH and the BLD shown northwest-southeast distribution. When the southwest wind strengthened, the high-values areas of the BLD in eastern LoLaP would move to north; atmospheric stability was bounded by the KMQSF, and the surface layer was dynamically stable (unstable) on the west (east) side of the KMQSF; the PM gradually increased from west to east, which was lower in westerly area and higher in easterly area. When

Table 1. SOM patterns of KMQSF and PM concentrations on November-next February 2014-2019.

\begin{tabular}{|c|c|c|c|c|c|c|}
\hline \multirow{3}{*}{ Pattern } & \multirow{3}{*}{ KMQSF location } & \multirow{3}{*}{$\begin{array}{l}\text { Sample } \\
\text { (day) }\end{array}$} & \multicolumn{4}{|c|}{ PM concentrations $\left(\mu \mathrm{g} \mathrm{m}^{-3}\right)$} \\
\hline & & & \multicolumn{2}{|c|}{ Kunming } & \multicolumn{2}{|c|}{ Guiyang } \\
\hline & & & $\mathrm{PM}_{10}$ & $\mathrm{PM}_{2.5}$ & $\mathrm{PM}_{10}$ & $\mathrm{PM}_{2.5}$ \\
\hline Pattern 1 & West to Kunming & 47 & $55.8 \pm 20.9$ & $35.0 \pm 13.7$ & $73.2 \pm 24.9$ & $48.5 \pm 16.5$ \\
\hline Pattern 2 & $\begin{array}{l}\text { Between western and eastern LoLaP, } \\
\text { near } 103.4^{\circ} \mathrm{E}\end{array}$ & 55 & $67.0 \pm 17.2$ & $36.8 \pm 11.5$ & $60.4 \pm 29.0$ & $42.0 \pm 21.8$ \\
\hline Pattern 3 & $\begin{array}{l}\text { Between western and eastern LoLaP, } \\
\text { near } 104.5^{\circ} \mathrm{E}\end{array}$ & 29 & $57.5 \pm 16.3$ & $27.6 \pm 6.8$ & $44.6 \pm 19.5$ & $28.6 \pm 12.3$ \\
\hline Pattern 4 & $\begin{array}{l}\text { Between western and eastern LoLaP, } \\
\text { near } 104.9^{\circ} \mathrm{E}\end{array}$ & 99 & $51.4 \pm 15.1$ & $26.0 \pm 8.7$ & $45.9 \pm 24.4$ & $30.4 \pm 18.6$ \\
\hline Pattern 5 & $\begin{array}{l}\text { Between western and eastern LoLaP, } \\
\text { near } 105.3^{\circ} \mathrm{E}\end{array}$ & 63 & $50.1 \pm 16.1$ & $23.5 \pm 7.7$ & $68.7 \pm 25.2$ & $46.1 \pm 20.0$ \\
\hline Pattern 6 & North to Guiyang & 108 & $58.4 \pm 22.7$ & $28.3 \pm 10.9$ & $74.5 \pm 34.3$ & $46.7 \pm 25.4$ \\
\hline Pattern 7 & $\begin{array}{l}\text { North to Guiyang with strongest } \\
\text { southwesterly }\end{array}$ & 39 & $41.7 \pm 12.7$ & $23.6 \pm 7.4$ & $57.1 \pm 19.8$ & $38.4 \pm 16.0$ \\
\hline Pattern 8 & $\begin{array}{l}\text { Between western and eastern LoLaP, } \\
\text { near } 104.9^{\circ} \mathrm{E} \text {, but being weaker }\end{array}$ & 82 & $63.3 \pm 24.8$ & $34.7 \pm 14.2$ & $87.0 \pm 32.2$ & $55.8 \pm 22.1$ \\
\hline Pattern 9 & Non-KMQSF & 72 & $72.3 \pm 26.6$ & $39.6 \pm 15.4$ & $96.1 \pm 34.1$ & $60.7 \pm 22.1$ \\
\hline
\end{tabular}




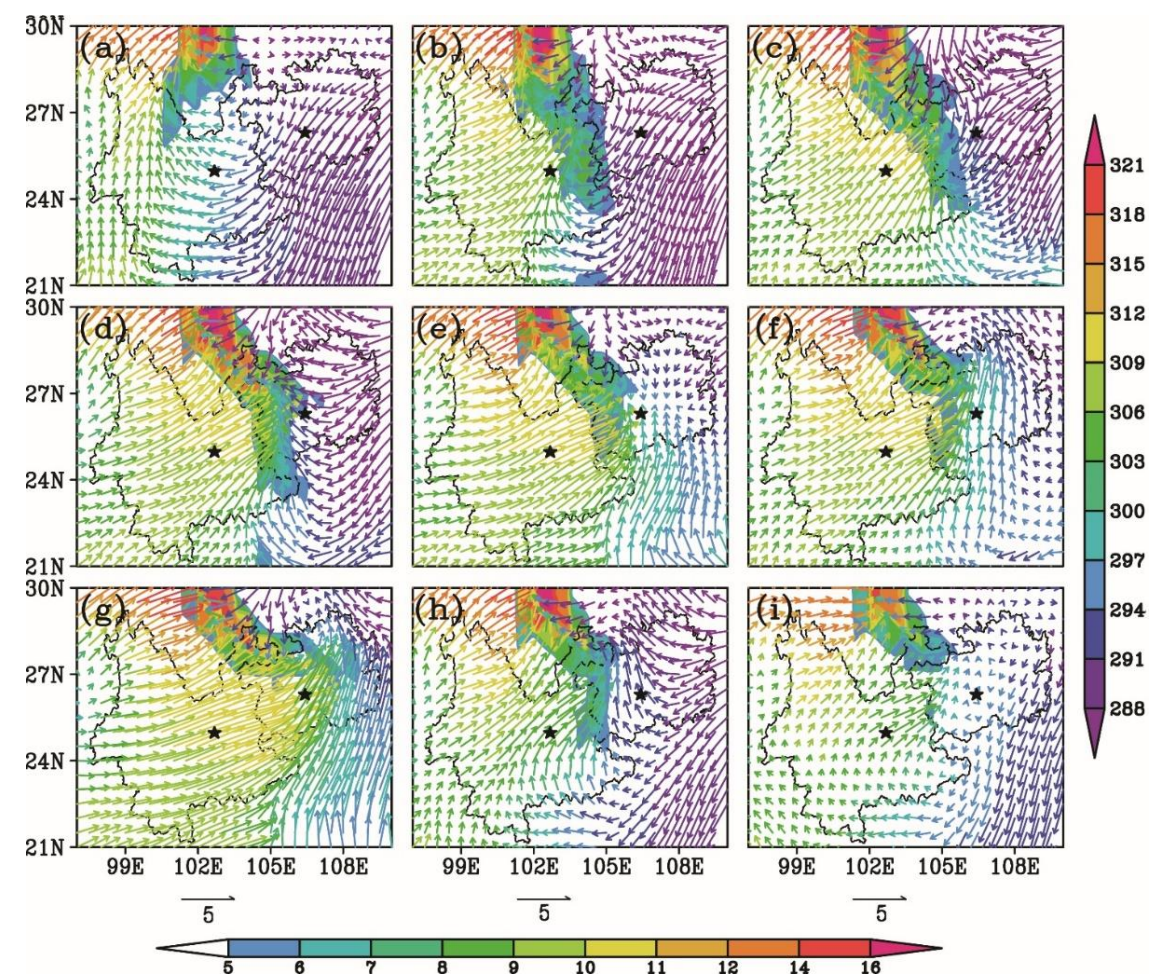

Fig. 8. (a-i) The distribution of horizontal potential temperature gradient (K 100-km ${ }^{-1}$; shaded, horizontal bar), wind $\left(\mathrm{m} \mathrm{s}^{-1}\right.$ ) and temperature (K; vertical bar) under nine SOM patterns of KMQSF (Pattern 1-9).

the KMQSF moved to the region west to Kunming or near Kunming represented by Pattern 1 and 2 (Figs. 9(a) and 9(b)), the high PM area was obviously pushed toward western LoLaP (Figs. 8(a) and $8(\mathrm{~b}))$ with daily mean $\mathrm{PM}_{10}$ and $\mathrm{PM}_{2.5}$ of $55.8 \pm 20.9$ and $35.0 \pm 13.7 \mu \mathrm{g} \mathrm{m}^{-3}$ in Kunming (Table 1). When both the southwest wind and northeast wind was the strongest, represented by Pattern 3 and 4, the BLD between western and eastern LoLaP was higher than $15 \times 10^{4} \mathrm{~J} \mathrm{~m}^{-2}$, associated by a PBLH higher than $300 \mathrm{~m}$ in the region east to the frontal line of the KMQSF (Figs. 9(c) and 9(d)), the PM was dissipated in whole LoLaP, with low values of PM covering LoLaP from southwest to northeast (Figs. 10 (c) and 10 (d)), in which the daily mean $\mathrm{PM}_{10}$ and $\mathrm{PM}_{2.5}$ concentrations were $44.6 \pm 19.5$ and $28.6 \pm 12.3 \mu \mathrm{g} \mathrm{m}^{-3}$ in Guiyang in Pattern 3, and $51.4 \pm 15.1$ and $26.0 \pm 8.7 \mathrm{~g} \mathrm{~m} \mathrm{~m}^{-3}$ in Kunming in Pattern 4 (Table 1). When the southwesterly gradually strengthened, represented by Pattern 6 to 7, the BLD in LoLaP increased from $9 \times 10^{4} \mathrm{~J} \mathrm{~m}^{-2}$ to 21 $\times 10^{4} \mathrm{~J} \mathrm{~m}^{-2}$, associated by an increase of the PBLH from $100 \mathrm{~m}$ to $200 \mathrm{~m}$ (Figs. 9(f) and 9(h)), the daily mean $\mathrm{PM}_{2.5}$ concentrations decreased from $28.3 \pm 10.9$ to $23.6 \pm 7.4 \mu \mathrm{g} \mathrm{m}^{-3}$ in Kunming and decreased from $46.7 \pm 25.4$ to $38.4 \pm 16.0 \mu \mathrm{g} \mathrm{m}^{-3}$ in Guiyang. Pattern 8 was similarly with Pattern 9 with much stronger wind and lower PM.

There were 72 days in Pattern 9, in which the KMQSF disappeared between western and eastern LoLaP, associating with lower southerly in LoLaP (Fig. 8(i)). The horizontal wind shear still existed in eastern LoLaP, but the horizontal potential temperature gradient was very low. The PM in LoLaP reached the highest value in Pattern 9 (Fig. 10(i)), associating with the lowest PBLH below $100 \mathrm{~m}$ and the weakest BLD less than $6 \times 10^{4} \mathrm{~J} \mathrm{~m}^{-2}$, and almost the whole region was dynamically stable (Fig. 9(i)), in which the difference of the PBLH and the BLD between western and eastern LoLaP was ignorable. The $\mathrm{PM}_{10}$ and $\mathrm{PM}_{2.5}$ significantly accumulated under such stable boundary layer to $72.3 \pm 26.6$ and $39.6 \pm 15.4 \mu \mathrm{g} \mathrm{m}^{-3}$ in Kunming, and $96.1 \pm 34.1$ and $60.7 \pm$ $22.1 \mu \mathrm{g} \mathrm{m}^{-3}$ in Guiyang, respectively (Table 1). Furthermore, Pattern 9 showed that it was westerly between Kunming and Guiyang on average; in fact, there were 9 days when it was weak easterly and 63 days when it was weak westerly. The daily mean $\mathrm{PM}_{10}$ and $\mathrm{PM}_{2.5}$ concentrations were $67.6 \pm 31.1$ and $43.6 \pm 22.7 \mu \mathrm{g} \mathrm{m}^{-3}$ in Kunming with weak easterly. The daily mean $\mathrm{PM}_{10}$ and $\mathrm{PM}_{2.5}$ concentrations were $72.9 \pm 26.2$ and $39.1 \pm 14.3 \mu \mathrm{g} \mathrm{m}^{-3}$ in Kunming with weak westerly. 

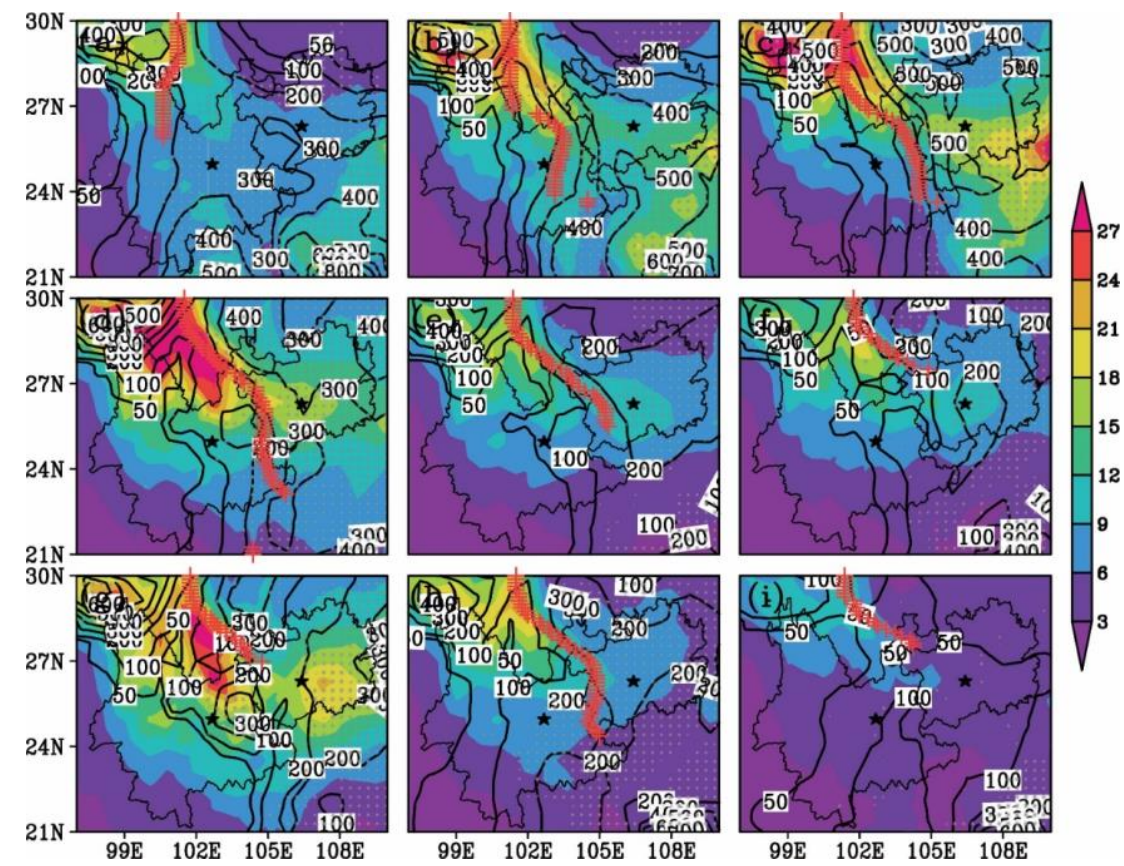

Fig. 9. (a-i) The distribution of boundary layer height ( $\mathrm{m}$; contour), boundary layer dissipation $\left(10^{4} \mathrm{~J} \mathrm{~m}^{-2}\right.$; shaded) and $\mathrm{Rb}(<0.25$; dots) under nine SOM patterns of KMQSF (Pattern 1-9). The red + represents the location of the KMQSF.
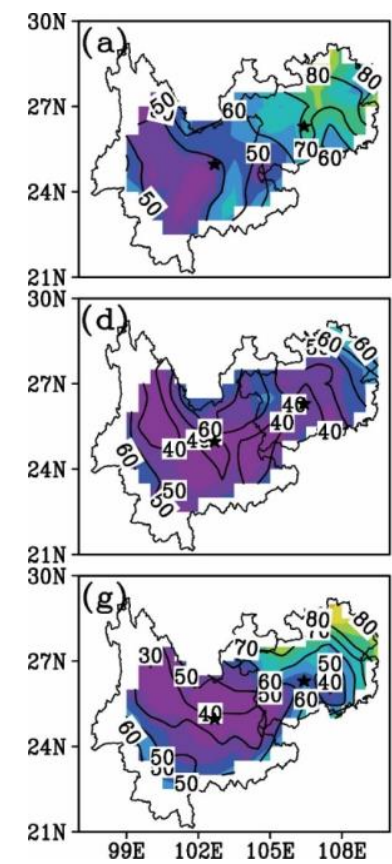
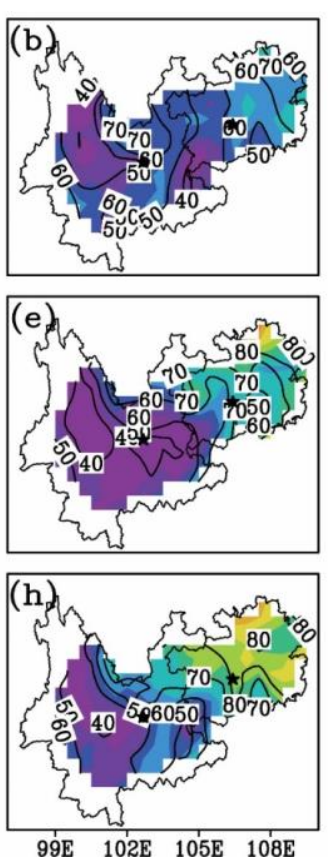

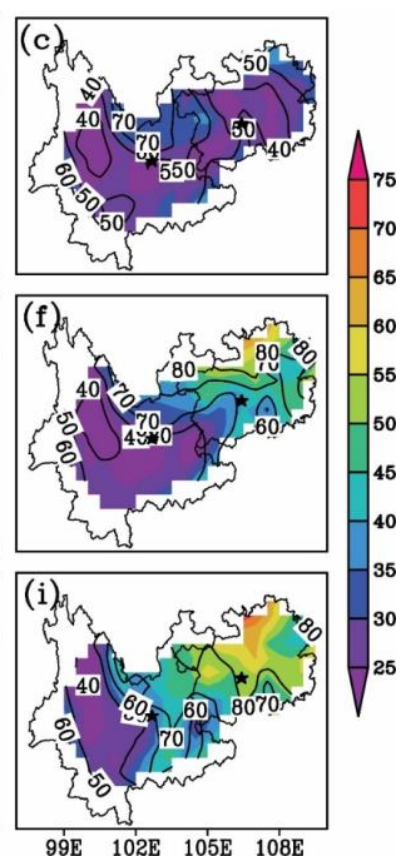

99E $102 \mathrm{E} \quad 105 \mathrm{E} \quad 108 \mathrm{E}$

Fig. 10. (a-i) The distribution of $\mathrm{PM}_{10}\left(\mu \mathrm{g} \mathrm{m}^{-3}\right.$; contour) and $\mathrm{PM}_{2.5}\left(\mu \mathrm{g} \mathrm{m}^{-3}\right.$; shaded) in LoLaP under nine SOM patterns of KMQSF (Pattern 1-9).

In general, when the KMQSF reached Kunming, the pollution could be transported to western LoLaP from eastern LoLaP by easterly under unstable atmosphere. When the KMQSF was weaker or disappeared between western and eastern LoLaP, the wind was lower in LoLaP, associating with a low PBLH and a weak BLD; these facts resulted in stable atmosphere near the surface, which restrained pollutant dispersion and led to high PM values. When PM in eastern LoLaP was higher than in western LoLaP indicated by Pattern 8 and 9 , the pollutant could not be transported by the southwest wind from eastern LoLaP to western LoLaP; therefore, the local accumulation 
should be the important reason inducing high PM concentration in Kunming. In general, the pollution in the Pattern 8 and 9 was induced mainly by local sources in the western LoLaP and there was pollution transport in the eastern LoLaP, there was long-range transport from east to west in Pattern 1 and 2, there was transport from west to east in Pattern 6 and 7, the air converged near the KMQSF in other patterns, and the KMQSF could block airflow between western and eastern LoLaP. The pollution event on December 2016 exactly occurred in meteorological condition of Pattern 9 and was ended in Pattern 6. Pattern 9 appeared 20 days in November 2016 to February 2017, and the frequency was higher than other years. Furthermore, the PBLH was always lower in the west side of the KMQSF, and this fact indicated more stable air near the surface in western LoLaP than eastern LoLaP, but the PM in eastern LoLaP was always higher than in western LoLaP, which indicated the local pollution emission and pollution transport in eastern LoLaP should be stronger than in western LoLaP. In Pattern 8, the PM 10 and $\mathrm{PM}_{2.5}$ concentrations in Guiyang was 23.7 and $21.1 \mu^{-3} \mathrm{~m}^{-3}$ higher than those in Kunming, and in Pattern 9, the PM 10 and $\mathrm{PM}_{2.5}$ concentrations in Guiyang was 23.8 and $21.1 \mu \mathrm{g} \mathrm{m}^{-3}$ higher than those in Kunming.

In addition, a pollution event lasting for several days might include different KMQSF patterns. We find an example from December 24 to 27,2017 , with the daily mean $\mathrm{PM}_{2.5}$ concentrations in Kunming of $89.7,103.4,80.3$ and $81.7 \mu \mathrm{g} \mathrm{m}^{-3}$, respectively experienced temporal changes of Pattern 9, Pattern 8, and Pattern 9, respectively. Though this event also went through the weaker and even disappeared KMQSF with lower PBLH and weaker BLD, the atmospheric circulation was different from the event on December 4-10, 2016. A high pressure appeared in the middle north of the LoLaP on December 26, 2017; the sinking restrained the pollution dispersion and promoted this pollution event. The pollution source and meteorological condition might be different in different pollution event, which should be particularly analyzed through the whole continuous process.

\section{CONCLUSIONS}

Analyzing the $\mathrm{PM}_{10}, \mathrm{PM}_{2.5}$ and $\mathrm{PM}_{1}$ concentrations for November 2016-May 2017 in downtown Kunming (Donglu), we identified the causes of a pollution episode during 2016 and evaluated the relationship between the KMQSF and the fine particle concentrations on the LoLaP between November and February for the years 2014-2019. Our main conclusions can be summarized as follows:

1) The change in weather triggered the regional pollution episode that affected Kunming and Guiyang on December 8 and 9, 2016, during which the $\mathrm{PM}_{10}$ and $\mathrm{PM}_{2.5}$ concentrations synchronously increased across the entire LoLaP. Prior to this episode, both Kunming and Guiyang had experienced a brief precipitation event and low aerosol concentrations. Additionally, from December 4 till 9, the KMQSF weakened to the east of Kunming, and both Kunming and Guiyang exhibited low wind speed, low PBLH, weak BLD, high RH and ground temperature inversions. The meteorological conditions favored the accumulation of primary PM and secondary organic aerosol precursors as well as the formation and growth of fine secondary particles, which resulted in a light haze. Once the KMQSF intensified, the static and stable weather was interrupted by a strong westerly wind, and the haze dissipated.

2) From November till February between 2014 and 2019, the weakest westerly and easterly winds, lowest PBLH and weakest BLD occurred when the KMQSF was very weak and disappeared in the center of the LoLaP. This weather pattern was also associated with a dynamically stable atmosphere near the surface at night and maximum PM concentrations due to unfavorable boundary layer dispersion conditions. When the KMQSF approached Kunming from the eastern LoLaP, easterly winds transported pollutants to the western part of the region beneath an unstable atmosphere. When the KMQSF was more intense, both the easterly and the westerly winds were stronger, leading to low PM concentrations across the LoLaP. Identifying nine KMQSF synoptic weather patterns, we discovered that the pollution observed during Patterns 8 and 9 was mainly contributed by local emission on the western LoLaP and there was pollution transport from surrounding areas on the eastern LoLaP. We also observed long-range transport from the east to the west during Patterns 1 and 2 and in the opposite direction during Patterns 6 and 7. During the other weather patterns, 
the air masses converged near the KMQSF, which blocked airflow between the western and eastern parts of the LoLaP. Furthermore, the consistently low PBLH to the west of the KMQSF indicated that the air near the surface was more stable in the western than the eastern part of the LoLaP. Hence, we can infer that the PM pollution tends to be far more severe on the western LoLaP.

The near-surface wind speed determines the intensity of a front. The average wind speed near the surface has been decreasing by $0.087 \mathrm{~m} \mathrm{~s}^{-1}$ decade $^{-1}$ (1979-2015) across the world (excluding Australia; Dunn et al., 2016), by $0.07 \mathrm{~m} \mathrm{~s}^{-1}$ decade $^{-1}$ (1979-2015) in East Asia (Dunn et al., 2016) and by $0.08 \mathrm{~m} \mathrm{~s}^{-1}$ decade ${ }^{-1}$ in South Asia (Vautard et al., 2010). Additionally, the average wind speed dropped at a rate of $0.16 \mathrm{~m} \mathrm{~s}^{-1}$ decade $^{-1}$ from 1966 till 2011 in China $\left(70-135^{\circ} \mathrm{E}, 15-54^{\circ} \mathrm{N}\right.$; Liu et al., 2014), with a decrease of $0.24 \mathrm{~m} \mathrm{~s}^{-1}$ decade ${ }^{-1}$ from 1969 till 2009 in southwestern China $\left(75-110^{\circ} \mathrm{E}, 15-35^{\circ} \mathrm{N}\right.$; Yang et al., 2012). The frequency of stagnant air days and episodes in the Sichuan-Chongqing region, which is east of the KMQSF, also increased between 2007 and 2016, with linear slopes of 0.61 and $0.26 \mathrm{y}^{-1}$, respectively (Liao et al., 2018b). Therefore, the intensity of the KMQSF has diminished, allowing more opportunities for air pollutants to accumulate.

This study analyzed the influence of the KMQSF on the formation and development of a light haze during early December 2016, which arose partly from favorable meteorological and terrain conditions and increased PM concentrations across the entire LoLaP (Fig. 2). Although only one event occurred during the observation period, our results suggest that the LoLaP will experience frequent pollution episodes in the future if anthropogenic emissions continue increasing in combination with a continual weakening of the KMQSF. Thus, future research should emphasize obtaining long-term regional aerosol data to further understand the role of the KMQSF in the generation and dissipation of air pollution.

\section{ADDITIONAL INFORMATION}

\section{Funding}

This work was supported by the National Natural Science Foundation of China (41865001, 41875178, 41675149 and 41905120), Natural Science Foundation of Jiangsu Province (BK20181099) and the Program for Key Laboratory at the University of Yunnan Province.

\section{Declaration of Competing Interest}

The authors declare that they have no known competing financial interests or personal relationships that could have appeared to influence the work reported in this paper.

\section{Supplementary data}

The PM data collected qin this study is available at https://doi.org/10.6084/m9.figshar e.8872724.v1.

\section{ACKNOWLEDGMENTS}

The SRTM data is available at http://srtm.csi.cgiar.org/srtmdata/. The hourly meteorological data were obtained from the China meteorological data sharing service system (http://data.cma.cn/data). The hourly PM measurement in downtown Kunming were collected through the online access to ambient air monitoring data center (http://106.37.208.233:20035/), the ERA-Interim dataset is available at https://apps.ecmwf.int/datasets/data/interim-full-daily/, and the 48-h backward trajectories for Kunming and Guiyang were obtained at http://ready.arl.noaa.gov/hypub-bin/trajsrcm.pl.

\section{REFERENCES}

Acosta Navarro, J.C., Varma, V., Riipinen, I., Seland, Ø., Kirkevåg, A., Struthers, H., Iversen, T., Hansson, H.C., Ekman, A.M.L. (2016). Amplification of Arctic warming by past air pollution 
reductions in Europe. Nat. Geosci. 9, 277-281. https://doi.org/10.1038/ngeo2673

Appelhans, T., Sturman, A., Zawar-Reza, P. (2013). Synoptic and climatological controls of particulate matter pollution in a Southern Hemisphere coastal city. Int. J. Climatol. 33, 463-479. https://doi.org/10.1002/joc.3439

Bian, Q., Alharbi, B., Sharee, M.M., Husai, T., Pasha, M.J., Atwood, S.A., Kreidenweis, S.M. (2017). Sources of $\mathrm{PM}_{2.5}$ carbonaceous aerosol in Riyadh, Saudi Arabia. Atmos. Chem. Phys. 18, 39693985. https://doi.org/10.5194/acp-18-3969-2018

Che, H., Zhang, X., Li, Y., Zhou, Z., Qu, J.J., Hao, X. (2009). Haze trends over the capital cities of 31 provinces in China, 1981-2005. Theor. Appl. Climatol. 97, 235-242, https://doi.org/10.1007/s0 0704-008-0059-8

Davis, L.W. (2017). Saturday driving restrictions fail to improve air quality in Mexico city. Sci. Rep. 7, 41652. https://doi.org/10.1038/srep41652

Dee, D.P., Uppala, S.M., Simmons, A.J., Berrisford, P., Poli, P., Kobayashi, S., Andrae, U., Balmaseda, M.A., Balsamo, G., Bauer, P., Bechtold, P., Beljaars, A.C.M., van de Berg, L., Bidlot, J., Bormann, N., Delsol, C., Dragani, R., Fuentes, M., Geer, A.J., Haimberger, L., Healy, S.B., Hersbach, H., Hólm, E.V., Isaksen, L., Kållberg, P., Köhler, M., Matricardi, M., McNally, A.P., Monge-Sanz, B.M., Morcrette, J.J., Park, B.K., Peubey, C., de Rosnay, P., Tavolato, C., Thépaut, J.N., Vitart, F. (2011). The ERA-Interim reanalysis: Configuration and performance of the data assimilation system. Q. J. R. Meteorolog. Soc. 137, 553-597. https://doi.org/10.1002/qj.828

Ding, A., Wang, T., Xue, L., Gao, J., Stohl, A., Lei, H., Jin, D., Ren, Y., Wang, X., Wei, X., Qi, Y., Liu, J., Zhang, X. (2009). Transport of north China air pollution by midlatitude cyclones: Case study of aircraft measurements in summer 2007. J. Geophys. Res. 114, D08304. https://doi.org/10.102 9/2008jd011023

Ding, A.J., Fu, C.B., Yang, X.Q., Sun, J.N., Zheng, L.F., Xie, Y.N., Herrmann, E., Nie, W., Petäjä, T., Kerminen, V.M., Kulmala, M. (2013). Ozone and fine particle in the western Yangtze River Delta: An overview of $1 \mathrm{yr}$ data at the SORPES station. Atmos. Chem. Phys. 13, 5813-5830. https://doi.org/10.5194/acp-13-5813-2013

Duan, W., Wan, S., Duan, X. (2014). Characteristics and causes of ground inversion over Kunming Bazi basin. Yunnan Geog. Environ. Res. 26, 1-6.

Duan, X., Duan, W., Xing, D. (2017). A study of objective determination for the Kunming quasistationary frontline. Acta Meteorol. Sin. 75, 811-822. https://doi.org/10.11676/qxxb2017.055

Duncan, B.N., Lamsal, L.N., Thompson, A.M., Yoshida, Y., Lu, Z., Streets, D.G., Hurwitz, M.M., Pickering, K.E. (2016). A space-based, high-resolution view of notable changes in urban $\mathrm{NO}_{x}$ pollution around the world (2005-2014). J. Geophys. Res. 121, 976-996. https://doi.org/10.10 02/2015JD024121

Dunn, R.J.H., Azorin-Molina, C., Mears, C.A., Berrisford, P., McVicar, T.R. (2016). Surface winds (in "State of the climate in 2015"). Bull. Am. Meteorol. Soc. 97, S38-S40.

Engling, G., Zhang, Y.N., Chan, C.Y., Sang, X.F., Lin, M., Ho, K.F., Li, Y.S., Lin, C.Y., Lee, J.J. (2011). Characterization and sources of aerosol particles over the southeastern Tibetan Plateau during the Southeast Asia biomass-burning season. Tellus B 63, 117-128. https://doi.org/10.1111/j.16 00-0889.2010.00512.x

Fan, J., Rosenfeld, D., Yang, Y., Zhao, C., Leung, L.R., Li, Z. (2015). Substantial contribution of anthropogenic air pollution to catastrophic floods in Southwest China. Geophys. Res. Lett. 42, 6066-6075. https://doi.org/10.1002/2015GL064479

Francis, J.A., Skific, N., Vavrus, S.J. (2018). North American Weather Regimes Are Becoming More Persistent: Is Arctic Amplification a Factor? Geophys. Res. Lett. 45, 414-411, 422. https://doi.org/10.1029/2018gl080252

Gibson, P.B., Perkins-Kirkpatrick, S.E., Uotila, P., Pepler, A.S. and Alexander, L.V. (2017). On the use of self-organizing maps for studying climate extremes. J. Geophys. Res. 122, 3891-3903. https://doi.org/10.1002/2016jd026256

Gietl, J.K., Klemm, O. (2009). Analysis of traffic and meteorology on airborne particulate matter in Münster, northwest Germany. J. Air Waste Manage. Assoc. 59, 809-818. https://doi.org/10. 3155/1047-3289.59.7.809

Gong, D.Y., Wang, W., Qian, Y., Bai, W., Guo, Y., Mao, R. (2014). Observed holiday aerosol reduction and temperature cooling over East Asia. J. Geophys. Res. 119, 6306-6324. https://doi.org/10.1 002/2014JD021464 
Homeyer, C.R., Bowman, K.P., Pan, L.L. (2010). Extratropical tropopause transition layer characteristics from high-resolution sounding data. J. Geophys. Res. 115, 6306-6324. https://doi.org/10.1029/2009JD013664

Hou, P., Wu, S. (2016). Long-term Changes in Extreme air pollution meteorology and the implications for air quality. Sci. Rep. 6, 23792. https://doi.org/10.1038/srep23792

Jiang, N., Scorgie, Y., Hart, M., Riley, M.L., Crawford, J., Beggs, P.J., Edwards, G.C., Chang, L., Salter, D., Virgilio, G.D. (2017). Visualising the relationships between synoptic circulation type and air quality in Sydney, a subtropical coastal-basin environment. Int. J. Climatol. 37, 1211-1228. https://doi.org/10.1002/joc.4770

Jung, J., Lee, K., Cayetano, M.G., Batmunkh, T., Kim, Y.J. (2015). Optical and hygroscopic properties of long-range transported haze plumes observed at Deokjeok Island off the west coast of the Korean Peninsula under the Asian continental outflows. J. Geophys. Res. 120, 8861-8877. https://doi.org/10.1002/2015JD023154

Khan, M.F., Sulong, N.A., Latif, M.T., Nadzir, M.S.M., Amil, N., Hussain, D.F.M., Lee, V., Hosaini, P.N., Shaharom, S., Yusoff, N.A.Y.M., Hoque, H.M.S., Chung, J.X., Sahani, M., Tahir, N.M., Juneng, L., Maulud, K.N.A., Abdullah, S.M.S., Fujii, Y., Tohno, S., Mizohata, A. (2016). Comprehensive assessment of $\mathrm{PM}_{2.5}$ physicochemical properties during the Southeast Asia dry season (southwest monsoon). J. Geophys. Res. 121, 14589-14611. https://doi.org/10.1002/2016JD025894

Knippertz, P., Evans, M.J., Field, P.R., Fink, A.H., Liousse, C., Marsham, J.H. (2015). The possible role of local air pollution in climate change in West Africa. Nat. Clim. Chang 5, 815-822. https://doi.org/10.1038/nclimate2727

Lai, L.W. (2015). Fine particulate matter events associated with synoptic weather patterns, longrange transport paths and mixing height in the Taipei Basin, Taiwan. Atmos. Environ. 113, 5062. https://doi.org/10.1016/j.atmosenv.2015.04.052

Lau, W.K.M., Kim, K.M., Leung, L.R. (2017). Changing circulation structure and precipitation characteristics in Asian monsoon regions: greenhouse warming vs. aerosol effects. Geosci. Lett. 4, 28. https://doi.org/10.1186/s40562-017-0094-3

Lelieveld, J., Evans, J.S., Fnais, M., Giannadaki, D., Pozzer, A. (2015). The contribution of outdoor air pollution sources to premature mortality on a global scale. Nature 525, 367-371. https://doi.org/10.1038/nature15371

Li, X., Xia, X., Wang, L., Cai, R., Zhao, L., Feng, Z., Ren, Q., Zhao, K. (2015). The role of foehn in the formation of heavy air pollution events in Urumqi, China. J. Geophys. Res. 120, 5371-5384. https://doi.org/10.1002/2014jd022778

Li, Y., Lau, A., Wong, A., Fung, J. (2014). Decomposition of the wind and nonwind effects on observed year-to-year air quality variation. J. Geophys. Res. 119, 6207-6220. https://doi.org/1 $0.1002 / 2013 J D 021300$

Li, Z., Lau, W.K.M., Ramanathan, V., Wu, G., Ding, Y., Manoj, M.G., Liu, J., Qian, Y., Li, J., Zhou, T., Fan, J., Rosenfeld, D., Ming, Y., Wang, Y., Huang, J., Wang, B., Xu, X., Lee, S.S., Cribb, M., Zhang, F., Yang, X., Zhao, C., Takemura, T., Wang, K., Xia, X., Yin, Y., Zhang, H., Guo, J., Zhai, P.M., Sugimoto, N., Babu, S.S., Brasseur, G.P. (2016). Aerosol and monsoon climate interactions over Asia. Rev. Geophys. 54, 866-929. https://doi.org/10.1002/2015RG000500

Li, Z., Guo, J., Ding, A., Liao, H., Liu, J., Sun, Y., Wang, T., Xue, H., Zhang, H., Zhu, B. (2017). Aerosol and Boundary-Layer Interactions and Impact on Air Quality. Natl. Sci. Rev. 4, 810-833. https://doi.org/10.1093/nsr/nwx117

Liang, P., Zhu, T., Fang, Y., Li, Y., Han, Y., Wu, Y., Hu, M., Wang, J. (2017). The role of meteorological conditions and pollution control strategies in reducing air pollution in Beijing during APEC 2014 and Victory Parade 2015. Atmos. Chem. Phys. 17, 13921-13940. https://doi.org/10.5194/acp17-13921-2017

Liao, G., Zheng, F., Zeng, P., Mo, Y. (2018a). Weather types of haze days in Guangxi. Meteorol. Sci. Technol. 46, 149-154. https://doi.org/10.19517/j.16716345.20170133

Liao, T., Gui, K., Jiang, W., Wang, S., Wang, B., Zeng, Z., Che, H., Wang, Y., Sun, Y. (2018b). Air stagnation and its impact on air quality during winter in Sichuan and Chongqing, southwestern China. Sci. Total Environ. 635, 576. https://doi.org/10.1016/j.scitotenv.2018.04.122

Liu, J., Kuang, W., Zhang, Z., Xu, X., Qin, Y., Ning, J., Zhou, W., Zhang, S., Li, R., Yan, C., Wu, S., Shi, X., Jiang, N., Yu, D., Pan, X., Chi, W. (2014). Spatiotemporal characteristics, patterns, and causes of land-use changes in China since the late 1980s. J. Geogr. Sci. 24, 195-210. 
https://doi.org/10.1007/s11442-014-1082-6

Luo, Y., Zheng, X., Zhao, T., Chen, J. (2014). A climatology of aerosol optical depth over China from recent 10 years of MODIS remote sensing data. Int. J. Climatol. 34, 863-870. https://doi.org/10.1002/joc.3728

Lv, B., Cai, J., Xu, B., Bai, Y. (2017). Understanding the rising phase of the $\mathrm{PM}_{2.5}$ Concentration evolution in large China cities. Sci. Rep. 7, 46456. https://doi.org/10.1038/srep46456

Mattingly, K.S., Ramseyer, C.A., Rosen, J.J., Mote, T.L., Muthyala, R. (2016). Increasing water vapor transport to the Greenland Ice Sheet revealed using self-organizing maps. Geophys. Res. Lett. 43, 9250-9258. https://doi.org/10.1002/2016gl070424

Miao, Y., Hu, X.M., Liu, S., Qian, T., Xue, M., Zheng, Y., Wang, S. (2015). Seasonal variation of local atmospheric circulations and boundary layer structure in the Beijing-Tianjin-Hebei region and implications for air quality. J. Adv. Model. Earth Syst. 7, 1602-1626. https://doi.org/10.1002/20 $15 \mathrm{~ms} 000522$

Mizuno, T., Kondo, H. (1992). Generation of a local front and high levels of air pollution on the Kanto plain in early winter. Atmos. Environ. 26, 137-143. https://doi.org/10.1016/09601686(92)90266-N

Nudelman, H., Frizzola, J. (1974). An air pollution incident due to a stationary front. Air Repair 24, 140-144.

Özbay, B. (2012). Modeling the effects of meteorological factors on $\mathrm{SO}_{2}$ and $\mathrm{PM}_{10}$ concentrations with statistical approaches. Clean-Soil Air Water 40, 571-577. https://doi.org/10.1002/clen.20 1100356

Petaja, T., Jarvi, L., Kerminen, V.M., Ding, A.J., Sun, J.N., Nie, W., Kujansuu, J., Virkkula, A., Yang, X.Q., Fu, C.B., Zilitinkevich, S., Kulmala, M. (2016). Enhanced air pollution via aerosol-boundary layer feedback in China. Sci. Rep. 6, 18998. https://doi.org/10.1038/srep18998

Quan, J., Gao, Y., Zhang, Q., Tie, X., Cao, J., Han, S., Meng, J., Chen, P., Zhao, D. (2013). Evolution of planetary boundary layer under different weather conditions, and its impact on aerosol concentrations. Particuology 11, 34-40. https://doi.org/10.1016/j.partic.2012.04.005

Raaschou-Nielsen, O., Pedersen, M., Stafoggia, M., Weinmayr, G., Andersen, Z.J., Galassi, C., Sommar, J., Forsberg, B., Olsson, D., Oftedal, B., Krog, N.H., Aasvang, G.M., Pyko, A., Pershagen, G., Korek, M., De Faire, U., Pedersen, N.L., Ostenson, C.G., Fratiglioni, L., Sorensen, M., Eriksen, K.T., Tjonneland, A., Peeters, P.H., Bueno-de-Mesquita, H.B., Plusquin, M., Key, T.J., Jaensch, A., Nagel, G., Foger, B., Wang, M., Tsai, M.Y., Grioni, S., Marcon, A., Krogh, V., Ricceri, F., Sacerdote, C., Migliore, E., Tamayo, I., Amiano, P., Dorronsoro, M., Sokhi, R., Kooter, I., de Hoogh, K., Beelen, R., Eeftens, M., Vermeulen, R., Vineis, P., Brunekreef, B., Hoek, G. (2017). Outdoor air pollution and risk for kidney parenchyma cancer in 14 European cohorts. Int. J. Cancer 140, 1528-1537. https://doi.org/10.1002/ijc.30587

Salmond, J.A., Dirks, K.N., Fiddes, S., Pezza, A., Talbot, N., Scarfe, J., Renwick, J., Petersen, J. (2016). A climatological analysis of the incidence of brown haze in Auckland, New Zealand. Int. J. Climatol. 36, 2516-2526. https://doi.org/10.1002/joc.4509

Sheng, P., Miao, J., Li, J., Zhang, A., Sang, J., Pan, N. (2015). Atmospheric physics. Peking University Press, Beijing.

Shi, J., Ding, X., Zhou, Y., You R., Huang, L., Hao, J., Xiang, F., Yang, J., Shi, Z., Han, X., Ning, P. (2016). Characteristics of chemical components in $\mathrm{PM}_{2.5}$ at a plateau city, South-west China. Front. Environ. Sci. Eng. 10, 4. https://doi.org/10.1007/s11783-016-0841-2

Stull, R.B. (1988). An introduction to boundary layer meteorology. Springer Netherlands.

Tao, Y., Duan, X., Yao, Y., Duan, C., Ren, J., Chen, Y., He, H. (2018). The climate correlation analysis between the Cold Wave in Yunnan and Kunming Quasi-Stationary front. J. Catastrophol. 33, 99-105. https://doi.org/10.3969/j.issn.1000-811X.2018.02.018

Tavolato, C., Isaksen, L. (2010). ERA report series: Data usage and quality control for ERA-40, ERAInterim and the operational ECMWF data assimilation system. ERA Report Series, 44.

Thishan Dharshana, K.G., Kravtsov, S., Kahl, J.D.W. (2010). Relationship between synoptic weather disturbances and particulate matter air pollution over the United States. J. Geophys. Res. 115, D24219. https://doi.org/10.1029/2010jd014852

Tie, X., Huang, R.J., Cao, J., Zhang, Q., Cheng, Y., Su, H., Chang, D., Poschl, U., Hoffmann, T., Dusek, U., Li, G., Worsnop, D.R., O'Dowd, C.D. (2017). Severe pollution in China amplified by atmospheric moisture. Sci. Rep. 7, 15760. https://doi.org/10.1038/s41598-017-15909-1 
Vautard R., Cattiaux J.L., Yiou P., Thepaut J.N., Ciais P. (2010). Northern Hemisphere atmospheric stilling partly attributed to an increase in surface roughness. Nat. Geosci., 3, 756-761. https://doi.org/10.1038/NGEO979

Wang, J., Zhang, M., Bai, X., Tan, H., Li, S., Liu, J., Zhang, R., Wolters, M.A., Qin, X., Zhang, M., Lin, H., Li, Y., Li, J., Chen, L. (2017). Large-scale transport of $\mathrm{PM}_{2.5}$ in the lower troposphere during winter cold surges in China. Sci. Rep. 7, 13238. https://doi.org/10.1038/s41598-017-13217-2

Wolf, T., Esau, I., Reuder, J. (2014). Analysis of the vertical temperature structure in the Bergen valley, Norway, and its connection to pollution episodes. J. Geophys. Res. 119, 10645-10662. https://doi.org/10.1002/2014JD022085

Yang, X.M., Li, Z.X., Feng, Q., He, Y.Q., An, W.L., Zhang, W., Cao, W.H., Yu, T.F., Wang, Y.M., Theakstone, W.H. (2012). The decreasing wind speed in southwestern China during 1969-2009, and possible causes. Quat. Int. 263, 71-84. https://doi.org/10.1016/j.quaint.2012.02.020

Yang, X., Zhao, C., Guo, J., Wang, Y. (2016). Intensification of aerosol pollution associated with its feedback with surface solar radiation and winds in Beijing. J. Geophys. Res. 121, 4093-4099. https://doi.org/10.1002/2015JD024645

Zhang, B., Jiao, L., Xu, G., Zhao, S., Tang, X., Zhou, Y., Gong C. (2018a). Influences of wind and precipitation on different-sized particulate matter concentrations ( $\left.\mathrm{PM}_{2.5}, \mathrm{PM}_{10}, \mathrm{PM}_{2.5-10}\right)$. Meteorol. Atmos. Phys. 130, 383-392. https://doi.org/10.1007/s00703-017-0526-9

Zhang, Y., Wang, J., Yang, Y., Li, D., Wang, Y., Che, H., Deng, G. (2018b). Contribution distinguish between emission reduction and meteorological conditions to "Blue Sky". Atmos. Environ. 190, 209-217. https://doi.org/10.1016/j.atmosenv.2018.07.015

Zhu, Q., Lin, J., Shou, S., Tang, D. (2000). Principles and methods of synoptic Science. Meteorology Press, Beijing. 